\title{
Laser-Assisted Cold-Sprayed Corrosion- and Wear-Resistant Coatings: A Review
}

\author{
E.O. Olakanmi and M. Doyoyo
}

(Submitted July 30, 2013; in revised form March 4, 2014)

\begin{abstract}
Laser-assisted cold spray (LACS) process will be increasingly employed for depositing coatings because of its unique advantages: solid-state deposition of dense, homogeneous, and pore-free coatings onto a range of substrates; and high build rate at reduced operating costs without the use of expensive heating and process inert gases. Depositing coatings with excellent performance indicators via LACS demands an accurate knowledge and control of processing and materials' variables. By varying the LACS process parameters and their interactions, the functional properties of coatings can be manipulated. Moreover, thermal effect due to laser irradiation and microstructural evolution complicate the interpretation of LACS mechanical deformation mechanism which is essential for elucidating its physical phenomena. In order to provide a basis for follow-on-research that leads to the development of high-productivity LACS processing of coatings, this review focuses on the latest developments in depositing corrosion- and wearresistant coatings with the emphasis on the composition, structure, and mechanical and functional properties. Historical developments and fundamentals of LACS are addressed in an attempt to describe the physics behind the process. Typical technological applications of LACS coatings are also identified. The investigations of all process sequences, from laser irradiation of the powder-laden gas stream and the substrate, to the impingement of thermally softened particles on the deposition site, and subsequent further processes, are described. Existing gaps in the literature relating to LACS-dependent microstructural evolution, mechanical deformation mechanisms, correlation between functional properties and process parameters, processing challenges, and industrial applications have been identified in order to provide insights for further investigations and innovation in LACS deposition of wear- and corrosionresistant coatings.
\end{abstract}

Keywords corrosion- and wear-resistant coatings, laser-assisted cold spray (LACS), mechanical deformation mechanism, residual stresses, thermal softening

\section{Introduction}

Engineering components; in use in automotive, marine, aerospace, power generation, petrochemical, and mining industries; experience large thermal plastic cyclic strains during each mission cycle which may be further complicated by environmental degradation as they operate under severe conditions of high chamber pressure and heat fluxes. Consequently, they can become structurally weakened, unable to carry the mechanical loads at high temperature; while also exhibiting a diminished wear, oxidation, and corrosion resistance capability thereby resulting in catastrophic failure. These problems affect the operation of industries as huge financial fortunes are expended to replace the damaged parts; high man-hours are wasted in effecting repair of components; while the

E.O. Olakanmi and M. Doyoyo, Department of Mechanical Engineering Science, University of Johannesburg, Johannesburg 2006, South Africa. Contact e-mail: eolakanmi@uj.ac.za. production output drastically reduces due to plant shut down. To combat the problems experienced by these materials in service, oxidation (Ref 1)-, corrosion (Ref 2)-, and wear (Ref 3)-resistant coatings had been developed with a view to extending the operational life of critical components as well as increasing the reliability of the components; shortening plant maintenance turnaround time; and lowering operational cost. In addition, the development of suitable coatings via cost-effective fabrication techniques for these materials will allow them to run at higher temperatures thus resulting in increased thermal efficiency.

Laser-assisted cold spray (LACS) process is a relatively new trend in the field of laser material processing which is employed for surface modification and coating of engineering components for increased functionality. It could also be described as a hybrid coating deposition technique which combines the benefits of both cold-spraying (CS) and laser-softening processes. The increasing importance of both CS and hybrid LACS techniques for the deposition of coatings is evident in the increasing number of research articles published by both industrial and academic researchers over the past decade as shown in Fig. 1.

According to Lupoi and co-investigators (Ref 4), and Bray et al., (Ref 5), the increasing importance of LACS technique for the deposition of coatings could be attributed to the fact that it provides customers with near-netshape components which allow functional load-bearing testing or actual in-service use. Moreover, it is 


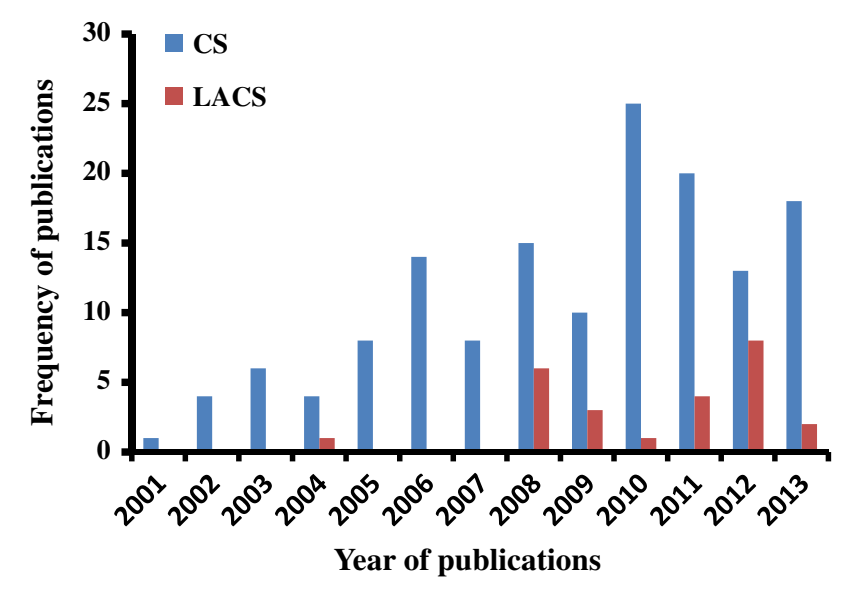

Fig. 1 Number of publications related to cold spray (CS) and laser-assisted cold spray (LACS) technique

characterized by technological and economic advantages, over conventional coating deposition methods, such as solid-state deposition of dense, homogeneous, and porefree coatings onto a range of substrates; high build rate at reduced operating costs without the use of expensive heating and process inert gases; less sensitivity to initial powders characteristics; consolidation of difficult-to-deposit powders; and marked comparative improvements in the properties of coating materials deposited. More importantly, lower processing temperature and shorter processing times associated with LACS technique permits the consolidation of coatings to full theoretical density with little grain growth and cleaned grain boundaries as demonstrated by Lupoi and co-investigators (Ref 4) via the deposition of nanostructured Stellite- 6 coatings on low-carbon steel substrates. The relatively short cycle of laser-powder interaction time also inhibits the occurrence of intermetallics or reaction of the coating materials with the substrate. The inhibition of the formation of intermetallics in LACS deposited coatings is consequent upon the usage of processing temperature which is lower than the melting of both the particles and the substrates. Consequently, both particle-substrate and particle-particle bondings take place in semi-molten state rather than full molten state. Therefore, non-formation of molten pool between the deposited particles and the substrates accounts for the avoidance of intermetallics in LACS deposited coatings. In addition, LACS technique can also produce fully consolidated coatings of uniform density or depositions with controlled porosity very rapidly to nearnet shape, with very low reject rates of the coatings. The implication of this for expensive materials is the appreciable cost savings obtained through reduced machining requirements and materials' scrap (Ref 4). Moreover, shorter processing times translate to productivity gains from the point of view of manufacturing engineer. Therefore, deposition of LACS higher quality coatings had been obtained at lower processing costs.

When employing a relatively new coating deposition technique such as LACS, many questions arise in our quest to gain an insightful understanding of the process with a view to optimizing the performance of the coatings: how do LACS process and material parameters influence the physical, microstructural, mechanical, and chemical properties of the coatings? How does the microstructure of LACS deposited coatings affect their wear and corrosion mechanisms? How does one evaluate these phenomena? How does one maximize the performance of the LACS deposited coatings against wear and corrosion? Answering these questions correctly may be the difference between successful LACS deposited coating and a premature catastrophic failure. Provided all these phenomena are considered to be self-related and, therefore, have a simultaneous action when coatings are subjected to their operating environments, then the complexity of this task appears to be extreme. A sound knowledge of materials science concepts owing to processing-microstructureproperty relationship of LACS deposited coatings is needed to achieve a reliable finished product. It is these issues which this review seeks to explore with particular emphasis on the wear- and corrosion-resistant alloyed powders by exploring the available literature on LACS process. In addition, studies dwelling mainly on cold spray, powder metallurgy $(\mathrm{P} / \mathrm{M})$, and laser material processing techniques (laser machining, texturing, and ablation) will also be employed to highlight the roles of process and material parameters in the deposition mechanism, as well as processing-microstructure-property relationship where current literature on LACS have not addressed such issues. In the next section, we present the historical development of LACS as well as the process description.

\section{Historical Developments of LACS and Process Description}

The deposition of coatings had been achieved via traditional and thermal approaches. The traditional approaches consist of electroplating and chemical vapor deposition (CVD) while the thermally sprayed coating techniques include plasma spray (PS), laser cladding (LC), and high-velocity oxy-fuel (HVOF). Moreover, hybrid laser deposition techniques in combination with PS (Ref 6) and HVOF (Ref 7) processes had been employed for enhancing particle-substrate bonding and coating performance or as a post-processing step to eliminate surface porosity from the microstructure of coatings (Ref 8). However, the traditional approaches are generally slow and expensive; while the thermally sprayed coating techniques are bedeviled with challenges such as component distortion, formation of undesirable intermetallic phases, poor mechanical properties, occurrence of high residual stresses, oxidation, and the requirement of high-purity inert environments to prevent oxidation during processing (Ref 9). Moreover, fabrication of coatings through the identified traditional and thermal approaches had been accomplished via several cycles with the necessity of optimizing each one in order to meet up their performance requirements in service. Therefore, the use of diverse equipment in processing coatings increases their cost 


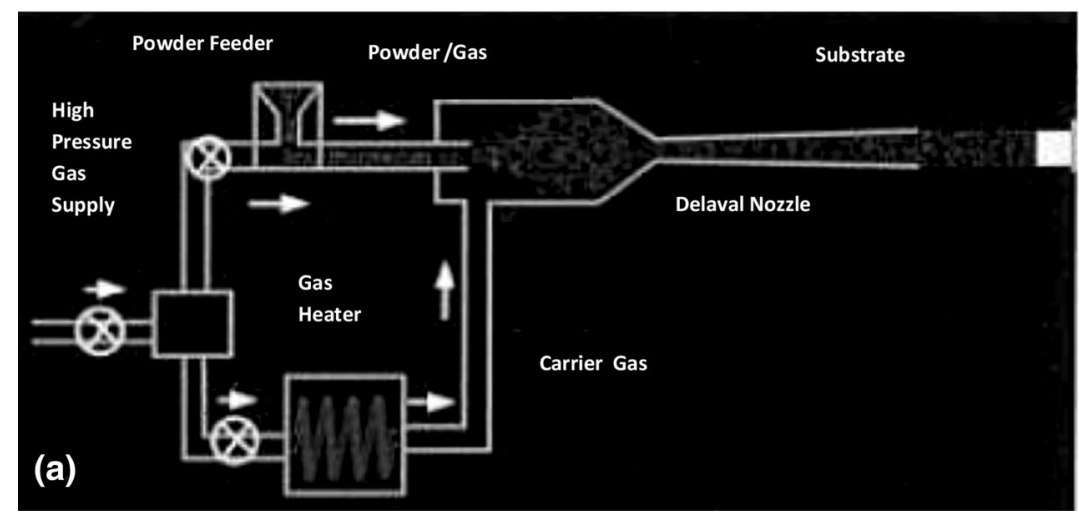

(b)

Fig. 2 Schematic diagrams of (a) cold spray system configuration and (b) particle bonding to the substrate during CS (Ref 10)

and hinders the repeatability of their structure and properties.

Cold spray process, a coating technology developed in the mid-1980s at the Institute for Theoretical and Applied Mechanics of the Siberian Division of the Russian Academy of Science in Novosibirsk (Ref 10) was then adopted to overcome the processing challenges of coatings highlighted in the preceding paragraph. The Russian scientists successfully deposited a wide range of pure metals, metallic alloys, polymers, and composites onto a variety of substrate materials. Meanwhile, a search through the literature reveals that high- and low-pressure cold spray had been identified as the methods of injecting the powdered materials into the nozzle (Ref 11). In high-pressure CS, powdered particles are injected prior to the spray converging-diverging De Laval nozzle throat from a preheated high-pressure gas supply whereas powdered particles are injected into the diverging section of the spray nozzle from a low-pressure gas supply while implementing a low-pressure CS process. As the propellant gas exits the nozzle throat, its expansion produces the conversion of enthalpy into kinetic energy which consequently accelerates the gas flow to the supersonic regime while reducing its temperature (Fig. 2a). Consequently, $\mathrm{CS}$ deposits coatings by entraining powder particles within a supersonically accelerated gas jet before it impinges on the deposition site at high velocities often approaching $1000 \mathrm{~m} / \mathrm{s}$ (Fig. 2a). The severe plastic deformation of particles which is responsible for their bonding with the substrate and subsequent formation of coatings (Fig. 2b) has been credited to the impact of the particles on the deposition site at a velocity above a critical value (Ref 9). It had been found that this critical velocity above which the impinging particles must be embedded into the substrate and bond with one another to form coating deposits is a function of the CS process parameters as well as the powdered and the substrate properties (Ref 9, 10). The mechanism of formation of CS coatings had been attributed to plastic deformation of impinging particles at the deposition site which leads to localized heating and flash welding at the coating-substrate interface (Ref 9,10). CS had also been credited with the achievement of very high coating deposition rates of the order of $5 \mathrm{~m}^{2} / \mathrm{min}(\operatorname{Ref} 12)$. CS offers a number of advantages over the thermal approaches of coating deposition as summarized in Table 1 , thereby making it one of the most competitive modern coating deposition technologies.

Despite the highlighted benefits of the CS process over other deposition techniques in Table 1 , there are also problems associated with CS. The problems include high operating costs accrued from gas consumption and heating. Moreover, bond strength and density are reduced when depositing hard materials and the coatings generally have large compressive residual stresses. In summary, high operating costs and a limited range of materials processable via CS have restricted the number of applications for which CS is economically viable (Ref 13 ). To address the problems associated with CS, LACS was developed to widen the range of materials that can be deposited using nitrogen and eliminate the need for gas heating, thereby reducing process costs and increasing the range of applications for which CS may prove unattractive (Ref 13). In summary, LACS is not meant to replace CS or any of the well-established thermal spray methods, rather it is expected to supplement and expand the range of applications for thermal spray.

In LACS, a laser heats both the particles and the substrate to between 30 and $80 \%$ of particle melting point (Fig. 3), thereby reducing the particle strength significantly, and allowing the particles to deform and build up a coating at an impact velocity about half of those used in CS. Among the merits of LACS process are increased ranges of materials for LACS processing compared to CS; reduced gas and equipment costs; high deposition rate; and retention of all the advantages associated with CS coatings by LACS deposited coatings. Figure 4 illustrates the capability of LACS process to deposit a pore- and crack-free Al$12 \mathrm{wt}$ \% Si coating on the stainless steel substrate for lowtemperature corrosion-resistant applications.

Three variants of LACS process are hereby identified on the basis of the arrangement of the laser beam and the cold spray gun or the time at which laser irradiation is applied to the cold spray-deposited coatings. For instance, Olakanmi et al., (Ref 14) and Christoulis et al., (Ref 15, 
Table 1 Comparative analysis of some thermal spray coating deposition techniques with cold spray process (Ref 12)

\begin{tabular}{|c|c|c|c|c|}
\hline Process feature & Cold spray & HVOF & Plasma & Arc spraying \\
\hline Bonding mechanism & Mechanical/chemical & Mechanical & Metallurgical & Metallurgical \\
\hline Maximum thickness & $0.05-10 \mathrm{~mm}$ & $<1.5 \mathrm{~mm}$ & $<0.5 \mathrm{~mm}$ & $0.1 \mathrm{~mm}$ \\
\hline Surface finish & $<1 \mu \mathrm{m}$ & $1.3-2.0 \mu \mathrm{m} \mathrm{Ra}$ & $13.0 \mu \mathrm{m} \mathrm{Ra}$ & $2.0 \mu \mathrm{m} \mathrm{Ra}$ \\
\hline Deposition rate & $1-10 \mathrm{~kg} / \mathrm{h}$ & $1-5 \mathrm{~kg} / \mathrm{h}$ & $2-7 \mathrm{~kg} / \mathrm{h}$ & $5-60 \mathrm{~kg} / \mathrm{h}$ \\
\hline Deposition efficiency & $>95 \%$ & $50-70 \%$ & $30-60 \%$ & $35-65 \%$ \\
\hline Wear resistance & $50 \mathrm{~mm}^{3}$ & $27 \mathrm{~mm}^{3}$ & $10 \mathrm{~mm}^{3}$ & $6 \mathrm{~mm}^{3}$ \\
\hline Bond strength & 30-40 MPa & 30-70 MPa & $30-55 \mathrm{MPa}$ & 20-30 MPa \\
\hline Equipment cost & 40, 000 USD & 60,000 USD & 50, 000 USD & 10,000 USD \\
\hline Corrosion rate & $0.25 \mathrm{~m} \mathrm{p} \mathrm{y}$ & $3.5 \mathrm{~m} \mathrm{p} \mathrm{y}$ & $1 \mathrm{~m} \mathrm{p} \mathrm{y}$ & $2 \mathrm{~m} \mathrm{p} \mathrm{y}$ \\
\hline Porosity & $0.15 \%$ & $1.6-2 \%$ & $5 \%$ & $10-20 \%$ \\
\hline Oxygen content & $0.25 \%$ & $3 \%$ & $9 \%$ & $5-15 \%$ \\
\hline Conductivity & $85 \%$ & $45 \%$ & $15 \%$ & $60 \%$ \\
\hline Gas consumption & $1-5 \mathrm{~m}^{3}$ & $50 \mathrm{~m}^{3}$ & $1-5 \mathrm{~m}^{3}$ & $0.1-5 \mathrm{~m}^{3}$ \\
\hline Power consumption & $5-15 \mathrm{~kW}$ & $1-2 \mathrm{KW}$ & $30-100 \mathrm{KW}$ & $5-10 \mathrm{KW}$ \\
\hline Powder feed Rate & $25-75 \mathrm{~kg} / \mathrm{h}$ & $25 \mathrm{~kg} / \mathrm{h}$ & $15 \mathrm{~kg} / \mathrm{h}$ & $125-150 \mathrm{~kg} / \mathrm{h}$ \\
\hline Spray velocity & At least $500 \mathrm{~m} / \mathrm{s}$ & $750 \mathrm{~m} / \mathrm{s}$ & $500-700 \mathrm{~m} / \mathrm{s}$ & $800 \mathrm{~m} / \mathrm{s}$ \\
\hline Feedstock capability & $\begin{array}{l}\text { Metals, polymers, } \\
\text { and composites }\end{array}$ & $\begin{array}{l}\text { Metals and } \\
\text { ceramics }\end{array}$ & Metals and ceramics & Metals and ceramics \\
\hline Typical application & $\begin{array}{l}\text { Friction, impact, } \\
\text { abrasion, and corrosion }\end{array}$ & $\begin{array}{l}\text { Friction, abrasion, and } \\
\text { corrosion }\end{array}$ & $\begin{array}{l}\text { Friction, impact, abrasion, } \\
\text { corrosion, and cavitation }\end{array}$ & $\begin{array}{l}\text { Friction, impact, } \\
\text { abrasion, and corrosion }\end{array}$ \\
\hline
\end{tabular}

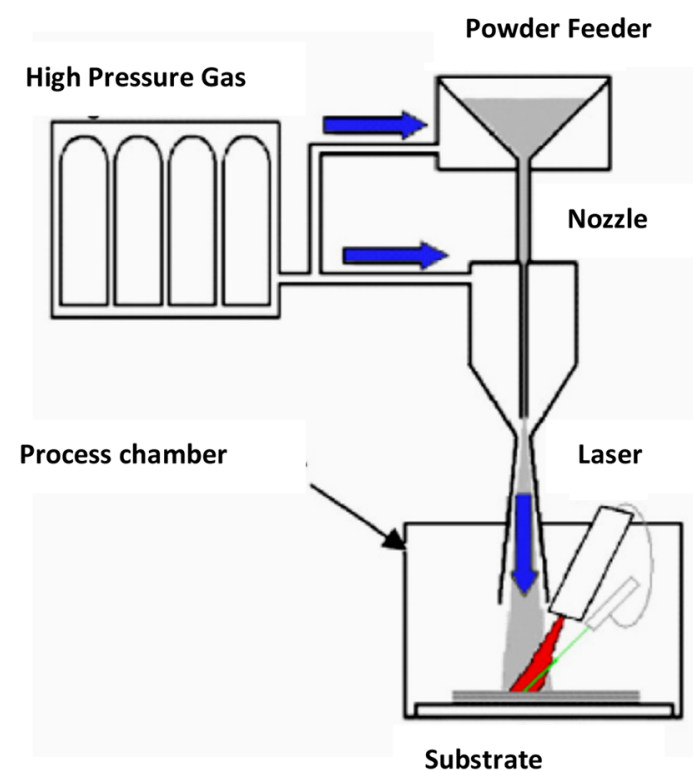

Fig. 3 Schematic of LACS (Ref 13)

16, 17) demonstrated LACS as a pretreatment method in which the laser beam passes milliseconds prior to the cold spray jet for deposition. Consequently, the laser beam softens the deposition site and thus the sprayed particles impinge on the softened substrate thereby forming a coating that is bonded to the substrate. In contrast, Lupoi et al., (Ref 4), and Bray et al., (Ref 5) described LACS as concentric coupling of the cold spray process with laser beam for the treatment of both the substrate and the gaspropelled particles. This process simultaneously reduces the particle strength significantly, and softens the deposition site, thereby allowing the particles to deform and build up a coating at an impact velocity which is typically

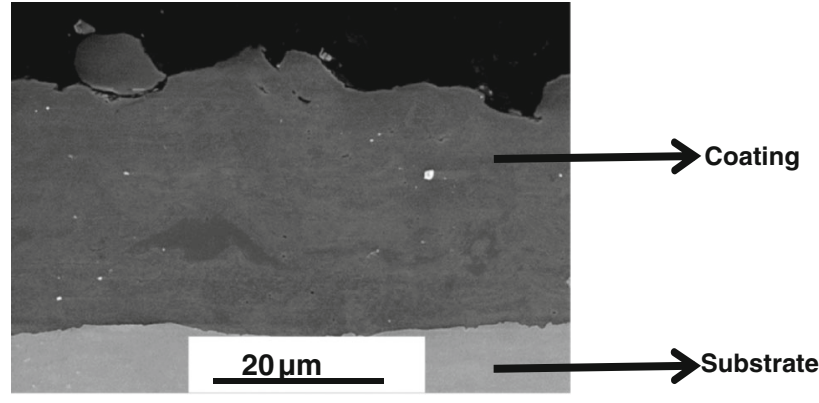

Fig. 4 SEM micrograph of a pore- and crack-free Al-12 wt. \% Si coating deposited on the stainless steel substrate via LACS (Ref 14)

$<500 \mathrm{~m} / \mathrm{s}$. Furthermore, Marrocco et al., (Ref 18) and Poza et al., (Ref 19) in implementing LACS employed post-cold spray laser treatment or laser glazing process to eliminate microscale porosity within the coating deposit via surface remelting. It is evident from the three variants of LACS identified so far that the combination of laser irradiation with the CS process or the application of laser glazing is implemented for the enhancement of the particle-substrate and particle-particle bonding strength with a view to optimizing the coating performance. In the next section, we present practical applications of LACS deposited coatings.

\section{Technological Applications of LACS Deposited Coatings}

Metallic coatings made of aluminum, titanium, nickel, cobalt, chromium, and their alloys and composites are among the most widely used materials for corrosion- and 
wear-resistant applications in chemical, petrochemical, and power plants; surface restoration; and deposition of electrical and thermal conductive coatings. For instance, 50/50 nickel-chromium ( $\mathrm{Ni}-\mathrm{Cr}$ ) alloys are suitable as wear, corrosion-, and oxidation-resistant coatings due to the formation of $\mathrm{Cr}_{2} \mathrm{O}_{3}$ which makes it suitable for use up to approximately $1200{ }^{\circ} \mathrm{C}$ (Ref 20, 21). Cr-Ti systems are also potential coating materials because they contain the intermetallic laves phase $\alpha-\mathrm{TiCr}_{2}$ which is hard, as well as corrosion, and oxidation resistant. The potentials of $\mathrm{Cr}-\mathrm{Ti}$ coatings and various binary phased crystalline coatings (comprising $\alpha-\mathrm{TiCr}_{2}$ and $\mathrm{Cr}$ (Ti) solid solutions) for resisting aqueous corrosion processes were demonstrated (Ref 22, 23). It was also claimed that passive films formed on $\mathrm{Cr}$ - Ti systems are more resistant to depassivation than those formed on pure $\mathrm{Cr}$ and $\mathrm{Ti}$ when immersed in chloride solutions (Ref 22). Therefore, these coatings are expected to be able to protect the plants' components operating in extreme conditions, which include high temperature and an aggressive environment, mainly due to their fine lamellar structure, homogeneous phase distribution, good lamellar adhesion, and high microhardness which will be imparted via LACS processing (Ref 4). Additional benefit of depositing coatings from these powders on less expensive substrates is the significant cost reductions compared to the use of bulk alloys.

With the environmental and health/safety regulations increasingly becoming stringent, both academic and industrial researchers are considering LACS as a potentially greener alternative for photovoltaic, wind, medical, and architectural applications. For instance, a group of researchers in Japan found that the photocatalytic performance of grid pattern laser-treated $\mathrm{TiO}_{2}-\mathrm{Zn}$ coating was far superior to the line pattern treated coatings produced via CS (Ref 24). Moreover, it is being anticipated that hydroxyapatite (HAP) may be deposited onto a number of substrates via LACS without compromising the integrity of HAP for biomedical applications. In architecture, LACS could also find application in the fabrication of unlimited esthetic metallic patterns on any metal or ceramic substrate.

Another prospective application of LACS is also in the fabrication of functionally graded thermal barrier coatings (TBCs) in which no single material satisfies all its operational requirements. In the case of TBCs which must consist of multiple layers of different materials with each layer performing erosion-resistant, thermal barrier, corrosion/oxidation-resistant, thermal stress control, and diffusion-resistant functions (Fig. 5). A typical TBC consists of $\mathrm{Sm}_{2} \mathrm{Zr}_{2} \mathrm{O}_{7} / \mathrm{YSZ} / \mathrm{NiCrAlY}$. Samarium zirconate $\left(\mathrm{Sm}_{2} \mathrm{Zr}_{2} \mathrm{O}_{7}\right)$ is the top ceramic coat $(\mathrm{A})$ with a low thermal conductivity and high phase stability which acts as a thermal insulator to protect the inner layers. The intermediate layer (B) consists of yttrium-stabilized zirconia (YSZ) which effectively prevents the top layer (A) from reacting with the bond coat $\mathrm{C}$ ( $\mathrm{NiCrAlY})$ thereby ensuring an excellent long-term thermal and chemical compatibility between the double ceramic layer coating systems. The bond coat $(\mathrm{C})$ prevents oxidation and corrosion of the substrate in the TBCs. Fabrication of functionally graded
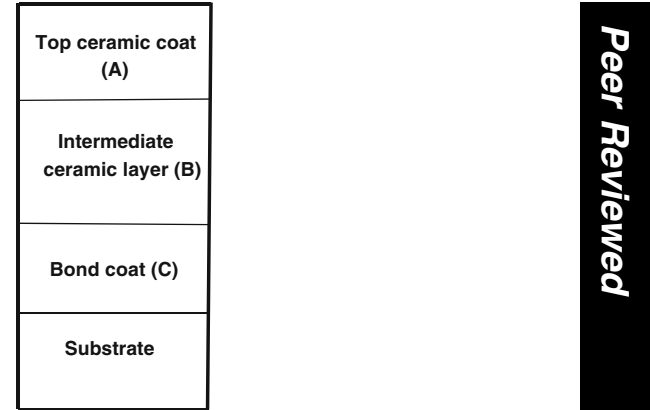

Fig. 5 Schematic description of a multilayer functionally graded thermal barrier coating (FG-TBCs) (top ceramic layer (A); intermediate layer (B); and bond coat $(\mathrm{C})$ )

TBCs can be achieved by the employment of an axisymmetric nozzle with two points of powder injection in a nozzle barrel with a constant cross section mounted to its diverging part as demonstrated by Klinkov et al., (Ref 25). Figure 6 shows the successful deposition of a composite coating from two significantly different materials (aluminum and copper) by injecting copper (harder and higher melting point particles) and aluminum (softer and lower melting particles) from the subsonic and supersonic parts of the nozzle. The details of achieving this via modification of the design of the nozzle will be discussed later in section 4.3.2.

\section{Effects of LACS Process and Materials' Parameters on the Deposition Mechanism and Functional Properties of Coatings}

The need to optimize the physical, mechanical, wear, corrosion, and high-temperature oxidation resistance properties of LACS deposited coatings, which are dependent on their deformation as well as the bonding mechanisms, demand that both process and materials' parameters are properly controlled. This section elucidates the roles of LACS process parameters (laser power, scanning speed, energy density, operating pressure, nozzle design, and transverse speed) and materials' properties (particle size and distribution, and powder density) in manipulating the deformation as well as the bonding mechanisms of the powdered particles to the substrate and then to each other. In the next section, the nature and the sequence of laser-material-cold gas interaction is presented in order to gain an insightful understanding of the LACS process.

\subsection{The Nature and the Sequence of LACS Process}

The nature of laser-material-cold gas interactions obtained in a LACS process is determined by the physical and chemical properties of the powders and the substrates; the laser radiation characteristics; deposition pressure; and 
(a)

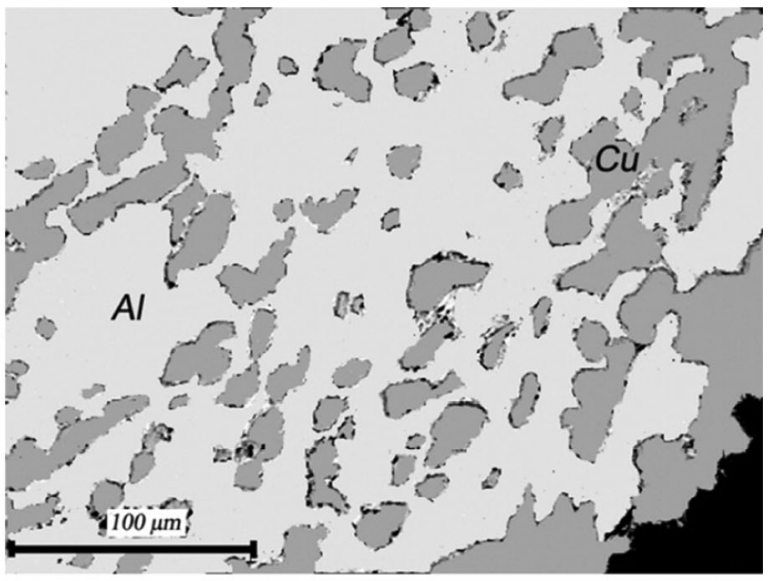

(b)

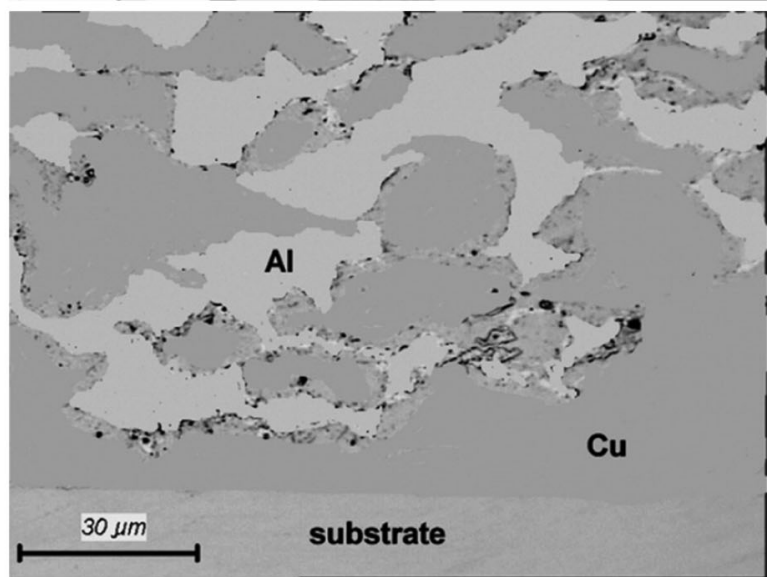

Fig. 6 Cross sections of the two-component copper-aluminum coating: (a) at the coating surface and (b) at the substrate-coating interface (Ref 24)

the particle velocity. In a pretreatment LACS process in which the laser beam passes milliseconds prior to the cold spray jet for deposition, the laser irradiation is mainly employed for substrate's surface cleaning or ablation with a view to removing contaminants such as oxides and oils via their transition from solid state to dispersed phases. Moreover, in a LACS process described as a concentric coupling of the cold spray process with laser beam, the laser irradiation softens both the particles and the substrate to between 30 and $80 \%$ of particle melting point $\left({ }^{\circ} \mathrm{C}\right)$. Considering the laser-material-cold gas interaction in the LACS process generally, the deposition mechanism could be said to have resulted from the phenomena of laser beam absorption, thermalization, and heat transfer. Each of these phenomena as related to the role of laser irradiation in the nature and the sequence of LACS process will be described briefly in subsequent paragraphs of this section. This will be achieved by employing various literatures dwelling on laser material processing (laser machining, texturing, and ablation). It is important to note that the fundamental principles of laser beam absorption, thermalization, and heat transfer associated with these processes are quite applicable to LACS process.
Laser beam absorption is a result of the interaction of the electric field of the light with the bound or free electrons of the material. The depth of penetration of irradiation on the materials is controlled by the laser beam wavelength (frequency), which is within a few nanometers for laser wavelengths incident on metals. Table 2 presents the absorption characteristics for some metallic materials using $\mathrm{Nd}$ :YAG and $\mathrm{CO}_{2}$ lasers in which the absorptance of metallic materials increases with decreasing laser beam wavelength. This is in agreement with the findings from the literature on the laser-material interaction when processed with either $\mathrm{CO}_{2}$ or Nd:YAG lasers (Ref 26). Moreover, the penetration depth of the thermal energy transferred by phonons of the metal over a given time duration is also a function of its thermal diffusivity and the laser beam pulse duration, which in turn depends on the laser frequency and energy (Ref 27). For instance, much of the laser energy intensity is absorbed in a low thermal diffusivity material suggesting effective surface softening of the material while the bulk remains cold and, therefore, unaffected (Ref 28). Other parameters which considerably control the laser beam absorption by a material are the skin depth, the surface temperature, the angle of incidence of the laser beam, and the substrate surface topography.

Consequently upon the conversion of laser radiation absorption in the substrate or powdered materials into heat via photon-electron, electron-electron, or electronphonon collisions, the thermalization process then occurs as the heat input rises with the kinetic or vibrational energy of the free electrons of the materials. It is the collisions and vibrations of the free electrons of the materials which eventually increase the temperature of a layer of thickness equal to the heat penetration depth. In the case of metal particles coated with brittle oxide or nitride film, the laser irradiation is expected to generate a temperature regime which is sufficiently high to cause the cracking of the film (Ref 29). Upon impact on the substrate, the thermally cracked brittle film is removed from the ductile metal particle in such a manner that exposes a clean nonoxidized powdered particle surface which is then bonded to the substrate surface. Brodmann (Ref 30) described this behavior of the thermally cracked brittle oxide film during impact with the substrate as "eggshell" model. According to Olakanmi et al., (Ref 14), particle-particle and particlesubstrate bonding will occur during LACS provided sufficient laser energy density/power is dissipated to cause the cracking of the brittle film, the brittle film thickness is greater than or equal to a critical value (depending on the material properties) and the metallic powder particles are uniformly coated with the brittle film. Therefore, the heat transfer mechanism in LACS process results in localized thermal gradient between the ductile metal particle and the brittle film covering it; thus, leading to occurrence of thermal shear or cracking in the film (Ref 29). It is pertinent to note that the short duration of the laser-material interaction in LACS process as well as the cooling effect of the process nitrogen gas minimize heat conduction into the substrate such that the formation of intermetallics between the deposited coatings and the substrate is minimized. 
Table 2 Absorption characteristics for some metallic materials using Nd:YAG and $\mathrm{CO}_{2}$ lasers (Ref 26)

\begin{tabular}{lcc}
\hline Material & $\begin{array}{c}\text { Nd:YAG } \\
(\boldsymbol{\lambda}=\mathbf{1 . 0 6} \boldsymbol{\mu m})\end{array}$ & $\begin{array}{c}\text { CO2 } \\
(\boldsymbol{\lambda}=\mathbf{1 0 . 6} \boldsymbol{\mu m})\end{array}$ \\
\hline $\mathrm{Cu}$ & 0.59 & 0.26 \\
$\mathrm{Fe}$ & 0.64 & 0.45 \\
$\mathrm{Sn}$ & 0.66 & 0.23 \\
$\mathrm{Ti}$ & 0.77 & 0.59 \\
$\mathrm{~Pb}$ & 0.79 & $\ldots$ \\
$\mathrm{Cu}-10 \mathrm{Al}$ (wt.\%) & 0.63 & 0.32 \\
$\mathrm{Fe}-3 \mathrm{C}-3 \mathrm{Cr}-12 \mathrm{~V}+10 \mathrm{TiC}$ (wt.\%) & 0.65 & 0.39 \\
$\mathrm{Fe}-0.6 \mathrm{C}-4 \mathrm{Cr}-2 \mathrm{Mo}-1 \mathrm{Si}+15 \mathrm{TiC}($ wt. \%) & 0.71 & 0.42 \\
$\mathrm{Fe}-1 \mathrm{C}-14 \mathrm{Cr}-10 \mathrm{Mn}-6 \mathrm{Ti}+66 \mathrm{TiC}$ (wt. \%) & 0.79 & 0.44 \\
\hline
\end{tabular}

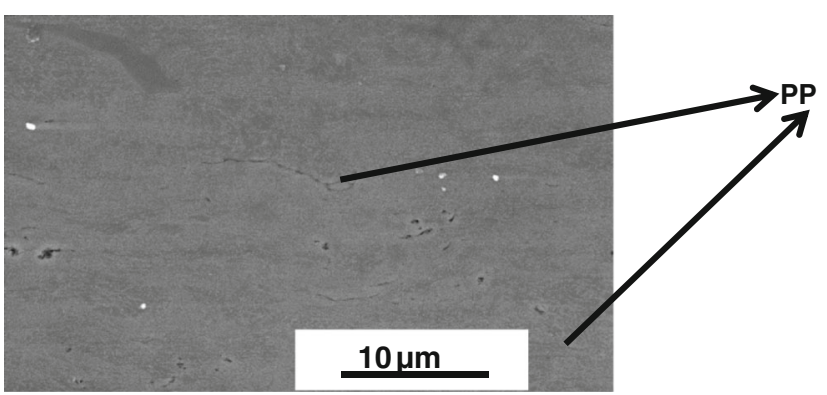

Fig. 7 Deformation mechanism in LACS deposited Al12 wt. $\%$ Si coating (Ref 14$)$

Moreover, the impingement of the high-velocity powdered particles on the substrate generates additional thermal energy in the LACS process in addition to the effect of laser irradiation. This results in an extremely fast increase of thermal energy in the materials' skin depth; nevertheless, it is not sufficient to have caused the melting of the material but rather soften both the impinging powdered particles and the substrate (Ref 14,31$)$. Consequently, no occurrence of significant heat-affected zones in the LACS deposited material (Ref 32 ) is in similarity to that encountered in short-pulsed laser ablation. The manipulation of the laser irradiation parameters and the deposition pressure is very important if the undesirable occurrence of metallurgical dilution in the LACS deposited coatings and the substrate materials via melting must be avoided. Meanwhile, Bray et al., (Ref 5) in concurrence with Olakanmi et al., (Ref 14) affirmed that the deposition mechanism in LACS process is controlled by particle and substrate softening via laser irradiation and adiabatic shearing phenomena in which deformation occurs partly at the top surface of each particle by flattening in a manner similar to thermally deposited coatings (see regions PP in Fig. 7) and also by forming a coherent layer via melting of particles in LACS deposited coating. Having elucidated the physics of laser-materials-cold gas interaction in LACS process, in the next section, the roles of laser parameters (e.g., laser power and scanning speed) in the development of the functional properties of LACS deposited coatings are explored.

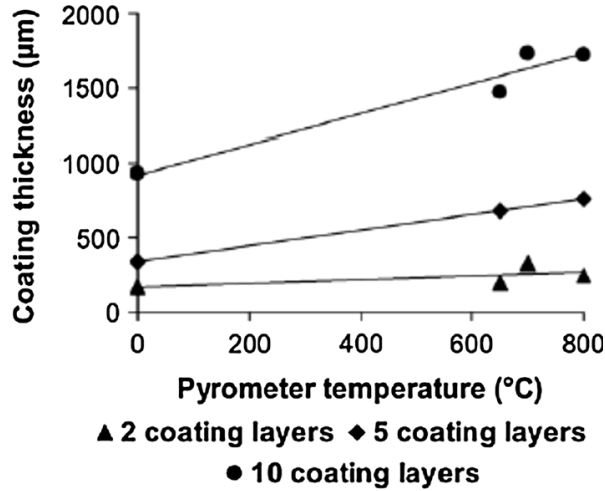

Fig. 8 Coating thickness of the copper coatings. The LALPCS coatings at pyrometer temperatures $650-800{ }^{\circ} \mathrm{C}$ (laser power 1.8 $2.4 \mathrm{~kW})$ and without the laser LPCS samples at $0{ }^{\circ} \mathrm{C}(\operatorname{Ref} 32)$

\subsection{Effects of Laser Parameters on the Functional Properties of the LACS Deposited Coatings}

4.2.1 Effects of Laser Power on Coating Deposition Efficiency and Build Rates. In a laser-assisted low-pressure cold spraying (LALPCS) process in which the laser irradiation interacted simultaneously with the cold spraying spot on the substrate, Kulmala and Vuoristo (Ref 33) discovered that increased laser power resulted in increased process temperature which enhanced the deposition efficiency (Fig. 8), and the densification (Fig. 9) of copper coatings due to the elimination of open porosity in comparison to the cold-sprayed coatings.

Bray et al., (Ref 5) also established that the build rate of LACS deposited titanium coatings increased with the deposition site temperature as the laser power increased (Fig. 10). Moreover, the build rate as well as porosity of LACS deposited coatings compare well to that obtained via CS, LC, HVOF, and PS techniques as revealed by Table 3. In summary, the deposition efficiency and the build rates obtained for LACS deposited coatings are quite comparable to other deposition techniques such CS, LC, and HVOF. The possibility of LACS process in depositing thick coatings rapidly without the formation of intermetallics suggests its capability to be employed in component repair or strengthening applications on heatsensitive parts. In addition, the formation of pore-free LACS deposited coatings is also considered a merit in its ability to resist chemical degradation. Nevertheless, the deposition efficiency and build rates of LACS deposited coatings could be investigated with other types of laser with a view to exploring the possibility of the heat intensity covering the entire width of the impinging powder stream.

4.2.2 Effects of Laser Power, Scanning Speed, and Energy Density on the Microstructure and Track Geometry of the LACS Deposited Coatings. Olakanmi and coinvestigators (Ref 14) evaluated the microstructural transition which occurred at the coating-substrate interface in LACS deposited $\mathrm{Al}-12$ wt. \% Si coatings as the laser power was varied between 2.0 to $3.0 \mathrm{~kW}$. In comparison to coatings fabricated at 2.0 and $3.0 \mathrm{~kW}$, only the coating 
(a)

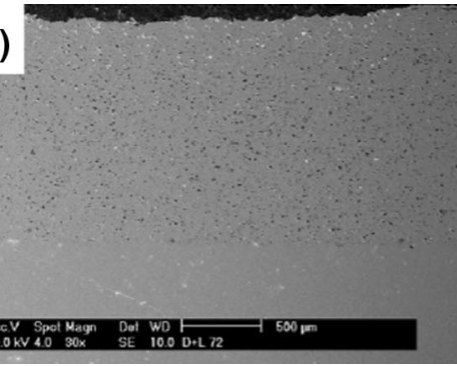

(b)

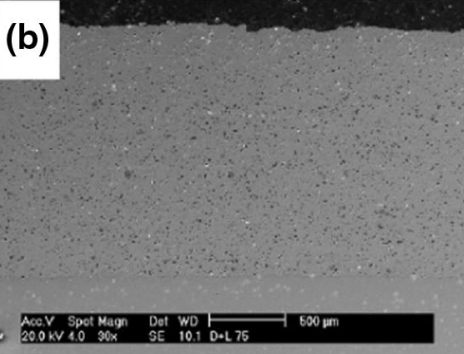

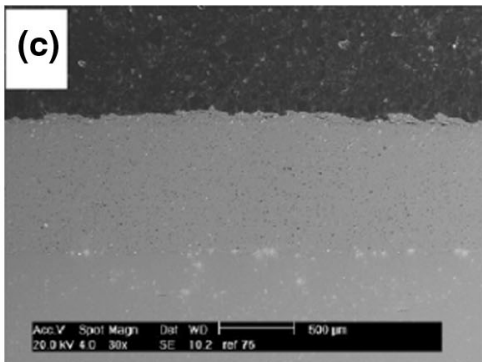

Fig. 9 SEM images showing the densification of LACS deposited copper coating at varying laser power which generated (a) $650{ }^{\circ} \mathrm{C}$; (b) $800{ }^{\circ} \mathrm{C}$; and (c) $0{ }^{\circ} \mathrm{C}($ Ref 32$)$

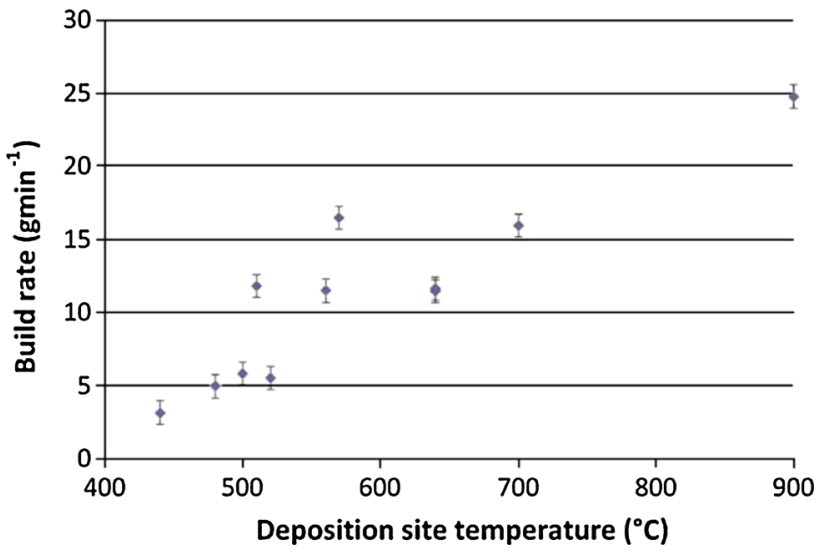

Fig. 10 Build rate vs. deposition site temperature for LCS deposited titanium (Ref 5)

Table 3 Typical build rates and porosity of LACS deposited coatings compared with other deposition techniques (Ref 5)

\begin{tabular}{lcc}
\hline Process & Build rate (g/min) & Porosity $(\%)$ \\
\hline LACS & $<45$ & $<1$ \\
CS & $<25$ & $<5$ \\
PS & $<100$ & $<7$ \\
LC & $<25$ & $<0.1$ \\
HVOF & $<120$ & $<1$ \\
\hline
\end{tabular}

produced with $2.5 \mathrm{~kW}$ was found to have a well-consolidated microstructure with no discernible differences in its cross section as evident by the absence of porosity, cracks, and unbounded particles (Fig. 11b). In addition, the bonding between the coating and the substrate appears to be strong and coherent as no porosity or crack could be located at the interface (Fig. 11e). The implication of this finding is that the degree to which both the cold-gas-entrained particles and the substrate are softened is a function of the applied laser power which determines the processing temperature. It is evident from Fig. 11e and $\mathrm{f}$ that the temperatures reached at the substrate, when 2.5 and $3.0 \mathrm{~kW}$ were applied for LACS deposition, softened the Al-12 wt.\%Si particles further thereby making it easier for them to be embedded on the substrate.
The outcome of this phenomenon is the coherent and strong bonding between the coating and the interface of the substrate as suggested by the microhardness values at the interface (Fig. 12). In the case of $2.0 \mathrm{~kW}$ (Fig. 11d), the presence of porosity at the interface shows that the applied laser power could not sufficiently soften both the Al-12 wt.\%Si particles and the substrate adequately enough to allow effective and coherent bonding of the coating with the substrate (see the interfacial microhardness for the coating sample produced with $2.0 \mathrm{~kW}$ ).

Poza et al., (Ref 34) also explored the role of scanning speeds in the microstructural development and mechanical behavior of laser-remelted Inconel 625 cold-sprayed coatings on stainless steel substrates. Figure 13(b)-(d) shows that the laser-remelted coatings obtained are denser in structure with a significant reduction of porosity, free of cracks, and consist of finer columnar dendritic microstructures in comparison to the cold-sprayed coating (Fig. 13a). Figure 13(b) is characterized with low secondary arms spacing, around $1 \mu \mathrm{m}$, as evidence of the occurrence of very high cooling rate achieved during the solidification process when coating was produced at $25 \mathrm{~mm} / \mathrm{s}$. The bright interdendritic areas in Fig. 13(b) were found to be enriched in $\mathrm{Nb}$ and Mo. These solute elements accumulated in front of the liquid-solid interface and segregated to the interdendritic areas during solidification.

Moreover, it was reported that substrate remelting was observed in substrate/coating zone (Fig. 13c) for scan speed ranging from 25 to $35 \mathrm{~mm} / \mathrm{s}$ close to surface regions which revealed a significant increase of $\mathrm{Fe}$ content in the laser-remelted bead while the laser treatment did not result in the remelting of the stainless steel substrate at higher scan speed range $(40-50 \mathrm{~mm} / \mathrm{s})$ because of lower heat inputs (Fig. 13d). It must be pointed out that the diffusion of Fe into the laser-remelted bead at $25-35 \mathrm{~mm} / \mathrm{s}$ is not desirable because this portends the formation of intermetallics which introduces thermally induced residual stresses, and poor mechanical properties into the coatingsubstrate interface. Therefore, when cold-sprayed coatings are being laser remelted with a view to eliminating surface porosity, appropriate choice of laser processing parameters must be made such that sufficient laser energy density is dissipated into remelting the top portion of the coatings 

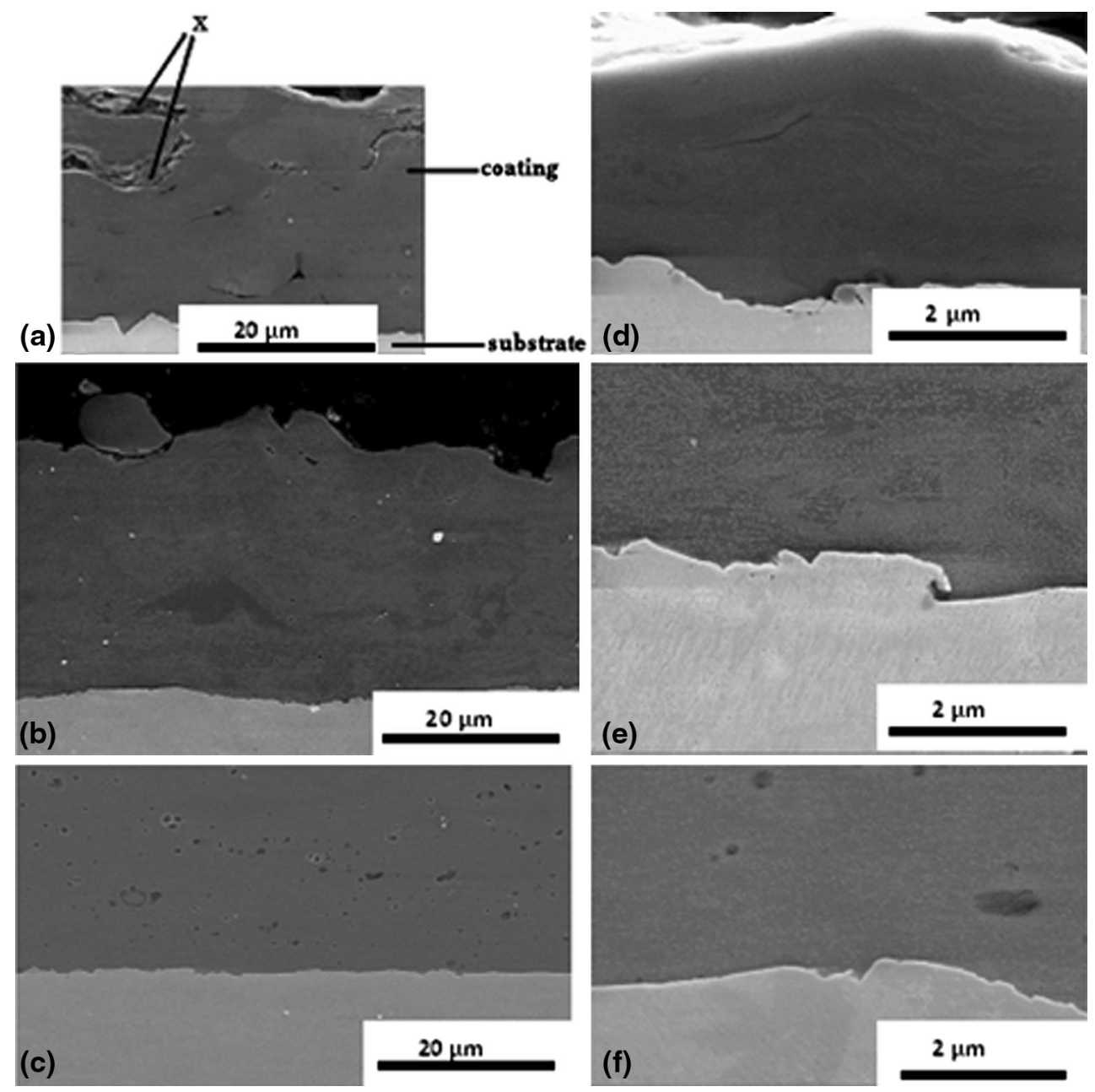

Fig. 11 Microstructures of LACS deposited Al-12 wt. \%Si coatings at varying laser powers (a, d) $2.0 \mathrm{~kW}$, (b, e) $2.5 \mathrm{~kW}$, and (c, f) $3.0 \mathrm{~kW}$ (X: unbounded particles) (Ref 14)

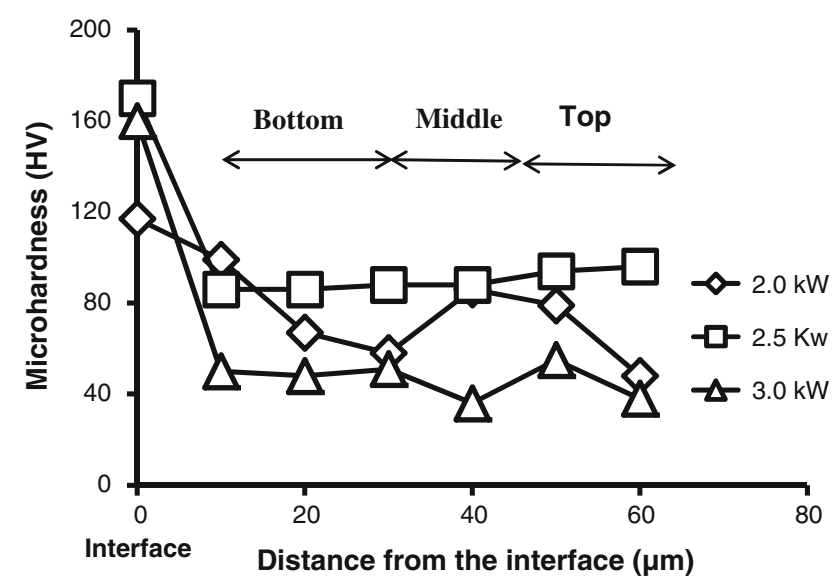

Fig. 12 Microhardness profiles of LACS deposited Al12 wt. $\%$ Si coatings at 2.0, 2.5, and $3.0 \mathrm{~kW}$ (Ref 14)

without engendering substrate-coating interaction resulting in interatomic diffusion of elements from the coatings to the substrates or vice-versa.
Marrocco et al., (Ref 18) employed an empirical power density relationship $P /(D V)^{1 / 2}$ to investigate the track geometry of laser-remelted cold-sprayed titanium coatings obtained at varying laser power $(P)$, scanning speed $(V)$, and beam diameter $(D)$. It was discovered that an increase of the $P /(D V)^{1 / 2}$ value correlates with an increase of the melting depth which results in the elimination of surface porosity and refinement of the grain structure upon solidification and cooling to room temperature. Moreover, increasing the laser power increases the depth and width of the melted region whereas increment in scanning speed resulted in reduction in the melted depth but with no change in track width. These findings from Marrocco et al., (Ref 18) highlight the need to understand the basic microstructural changes that occur in the development of coating track geometry when LACS process and materials parameters are varied. However, specific information on how this occurs in regards to a pretreatment LACS process or a LACS process described as a concentric coupling of the cold spray process with laser beam has not yet been established.

Similar to a laser welding process, the cooling rate during LACS should be predictable from the cross-sec- 

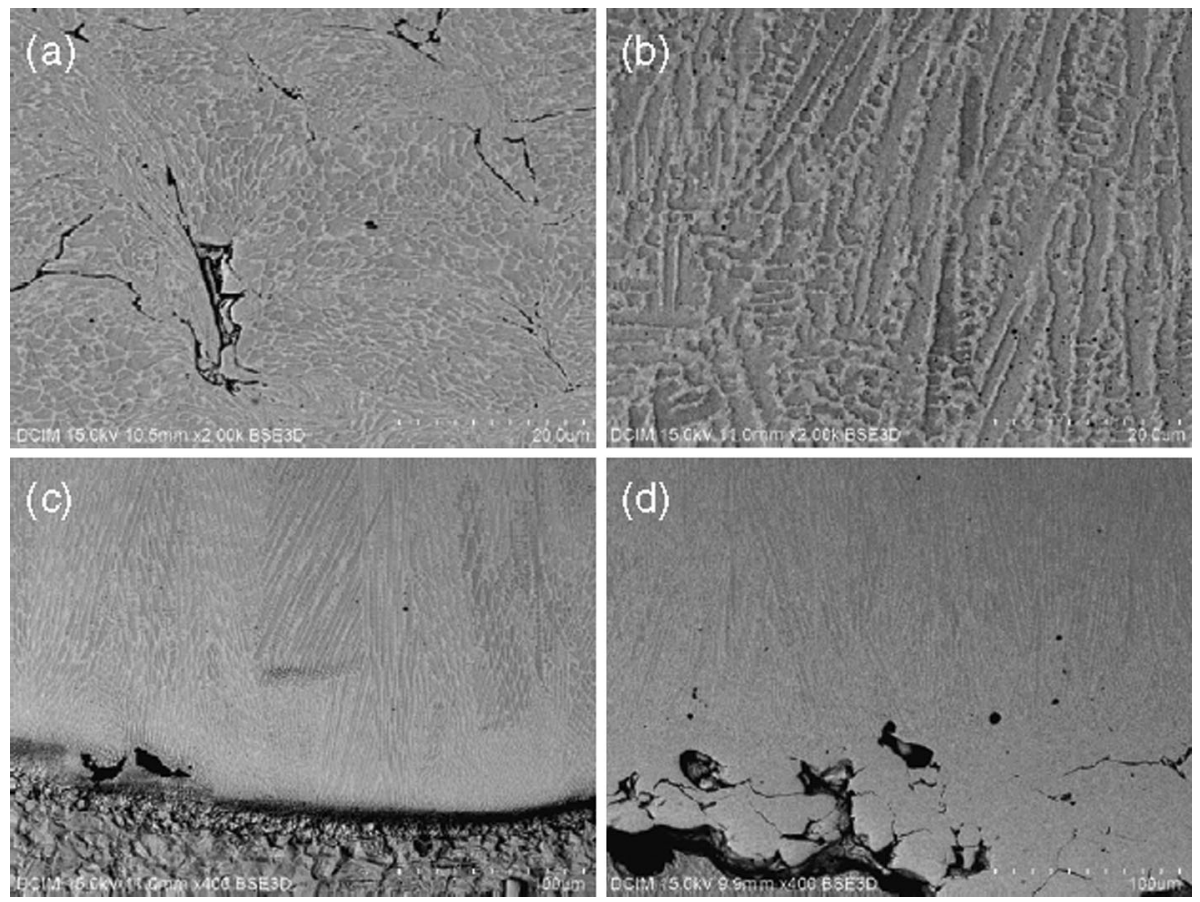

Fig. 13 SEM images of the as-sprayed and laser-remelted Inconel 625 coatings. (a) The as-sprayed coating showing a cold-worked dendritic microstructure; (b) columnar dendritic microstructure close to surface in the laser-remelted coating, scanning speed $25 \mathrm{~mm} / \mathrm{s}$; (c) substrate/coating area with substrate remelting at $25 \mathrm{~mm} / \mathrm{s}$; and (d) substrate/coating area without substrate remelting at $45 \mathrm{~mm} / \mathrm{s}$ (Ref 33)

tional area of the coating track, the dissipated energy density, the materials' properties, and the cooling effect of cold-sprayed nitrogen gas $\left(\mathrm{N}_{2}\right)$. Therefore, the cross-sectional area of the coating track together with its height and width are expected to affect the total shrinkage, which determines largely the residual stresses and thus the distortion depending on the choice of LACS process and materials' parameters. On this basis, it is envisaged that the degree of thermally induced stresses, distortion, and porosity are likely to be related more directly to the geometry of the coating rather than laser processing parameters. Moreover, materials' conductivity may also influence the nature of the coating geometry during LACS processing. For instance, the higher the heat conductivity of a material the lower is the penetration. In summary, it may be stated that the geometry of the LACS deposited coatings affect its functional properties and is dependent on LACS process and materials' parameters.

4.2.3 Mechanical Properties of LACS Deposited Coatings. Perton et al., (Ref 35) compared the individual and cumulative effects of in-situ pulsed laser ablation (PLA) and continuous laser preheating of the substrate surface a few milliseconds prior to the impact of the spray particles on the adhesion strength of cold-sprayed Ti-6Al-4V coatings. The outcome of the study revealed that laser ablation of the substrate before cold spraying led to a smooth surface which improved adhesion strength whereas employing in-situ laser ablation throughout the cold spray process resulted in a reduction of adhesion of the coatings. According to Perton and co-authors (Ref 35), the reduction in the adhesion strength of the coatings during in situ laser ablation was unexpected because the cleaning effect of PLA should allow an intimate and oxide-free bonding between the particles due to the removal of oxide films at the atomic scale on the particle and substrate surfaces by the high-velocity particle impact (Ref 36, 37, 38). Meanwhile, the increased adhesion strength reported when the PLA process was combined with increasing laser preheating temperature could be attributed to the fact that the laser heating helped to maintain the temperature and shockwave created by the PLA process thereby lengthening its duration. The high temperature of the laser beam would then disrupt the oxide films and other impurities on the substrate to prepare a very smooth surface, equivalent to the one obtained with polishing, with enhanced contact surface for particle deformation as well as adhesion. Perton and co-authors (Ref 35) then concluded that the negative effects associated with in situ laser ablation technique were mitigated by combining laser ablation and laser preheating. It is pertinent to note that the study of Perton and co-authors (Ref 35) highlighted the difference between the bond strength imparted on coatings by a pretreatment LACS process in which the laser beam passes milliseconds prior to the cold spray jet for deposition and the LACS process described as a concentric coupling of the cold spray process with laser beam.

Furthermore, the elastic modulus of the laser-remelted Inconel 625 cold-sprayed coatings increased by 10 and $6 \%$ over the bulk alloy, when scanning speeds were varied 


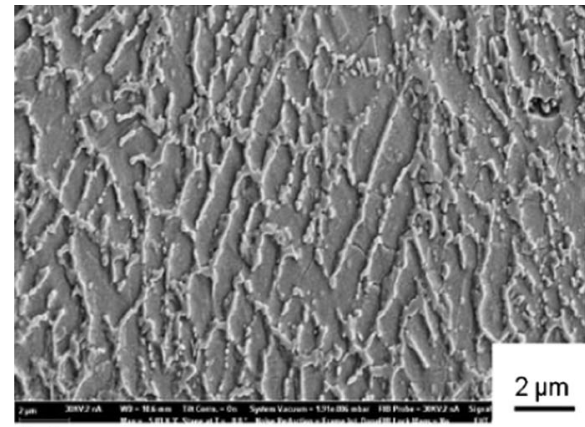

(a)

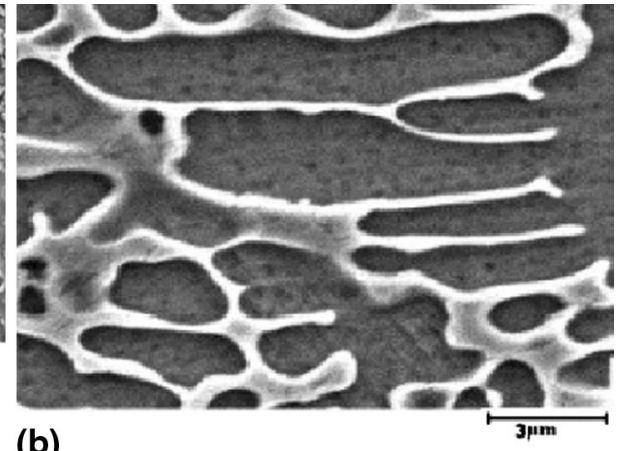

(b)

Fig. 14 SEM micrographs of coating. (a) SLD and (b) LC (Ref 38)

between 25 to 35 and 40 to $50 \mathrm{~mm} / \mathrm{s}$, respectively (Ref 34 ). This outcome could be attributed to the reduction in microstructural porosity at lower range of scanning speeds which resulted in longer duration of laser-material interaction. Meanwhile, the columnar dendritic microstructure reduced the hardness of the coating, although the values measured are still higher than those corresponding to the bulk alloy. Coating hardness was also reduced by approximately 30 and $20 \%$ when the scan speeds ranged from 40 to 50 and 25 to $35 \mathrm{~mm} / \mathrm{s}$, respectively. Higher hardness recorded at lower scanning speeds could be explained by the laser remelting of the steel substrate. Consequently, the Fe content in the coating was increased leading to an increment in hardness compared with the other laser treatment conditions.

Luo et al., (Ref 39) also evaluated the wear resistance of supersonic laser-deposited (SLD) stellite 6 coating via comparison with laser-clad (LC) coating. Findings from their study confirmed that the coatings deposited by SLD are characterized with a refined sub-micron scale microstructure (Fig. 14a) and have no dilution layer, while the LC coatings have carbide dendrites approximately $10 \mu \mathrm{m}$ thick (Fig. 14b) with higher dilution rate. Consequently, the microstructural differences in the coatings as a result of different deposition techniques account for the differences observed in the topography of their wear surfaces. For instance, coating deposited by SLD on the surface is believed to retain initial composition and or phases (Fig. 15), leading to a lower friction coefficient and weight loss in comparison to that of LC coating which contain coarse carbide dendrites (Fig. 16). Moreover, the wear tracks of coating deposited via LC revealed clear, deep parallel grooves; while the coating deposited via SLD exhibited debris gravitating together with worn mark showing thin and shallow grooves via spallation (Fig. 17). Finally, it is evident that the use of LACS deposition techniques of coatings has the potential to overcome all the drawbacks which are induced by the conventional thermal spray thereby imparting good wear resistance into coatings.

4.2.4 Effects of Laser Power on Corrosion and Chemical Properties of LACS Deposited Coatings. Marrocco and co-investigators (Ref 18) investigated the effect of post-deposition laser treatment on corrosion behavior of the coatings in 3.5 wt. $\% \mathrm{NaCl}$ by analyzing the pore structure evolution and microstructural changes. They reported that the as-sprayed titanium coatings could not provide favorable protection to the carbon steel substrate in the aerated $\mathrm{NaCl}$ solution, whereas the coatings with laser-treated surfaces provided barrier-like properties with corrosion values comparable to those of bulk titanium. The barrier-like properties of the laser-treated titanium coating during immersion in $\mathrm{NaCl}$ solution could be explained by the formation of a stable oxide film ( $\mathrm{TiO}$ phase) during laser irradiation of the as-sprayed coating.

Kulmala and Vuoristo (Ref 33) also explored the corrosion behavior of all LALPCS deposited copper coatings (irrespective of applied laser power) by exposing them to 3.5 wt. $\% \mathrm{NaCl}$ for 11 days with none of them showing open porosity while their open cell potentials were comparable to that of the bulk copper (Fig. 18). Furthermore, Kulmala and Vuoristo (Ref 33) also compared the functional performance of LALPCS deposited copper coatings with that of nickel. Although LALPCS deposited nickel coatings had denser surface compared to their coldsprayed counterparts as revealed by microstructural examination, the open cell potential tests confirmed the occurrence of open porosity in both cold-sprayed and laser-treated nickel samples irrespective of the applied laser power. The existence of open porosity in the laser-treated nickel samples which resulted in their poor corrosion resistance could presumably be attributed to the insufficient laser energy intensity that could not effect adequate thermal softening of nickel particles prior to their consolidation on the substrates. Hence, it is envisaged that the higher melting temperature of nickel required higher energy density than that dissipated in the study for effective softening of its particle prior to deposition.

Figure 19 compares the levels of oxygen in LACS deposited commercially pure titanium coatings at varying temperatures with cold-sprayed and HVOF deposited coatings, as well as the feedstock titanium powder. It is clear from Figure UJ that at the higher deposition temperature, the level of oxygen $(0.6 \mathrm{wt} \%)$ in the $1000 \mathrm{~W}$ $\left(900{ }^{\circ} \mathrm{C}\right)$ coating is similar to that of the $720 \mathrm{~W}\left(600{ }^{\circ} \mathrm{C}\right)$ coating. According to Bray et al., (Ref 5), this level of oxygen is comparable to that found in cold-sprayed titanium coatings and lower than coatings of a similar density 


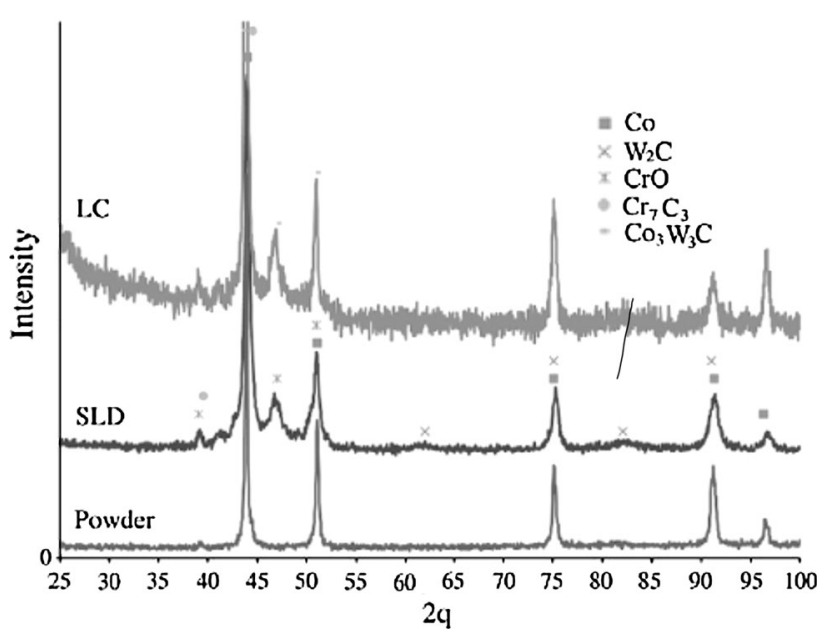

Fig. 15 X-ray diffraction (XRD) analysis of Stellite-6 powder and coatings produced with supersonic laser deposition (SLD) and laser cladding (LC) (Ref 38)

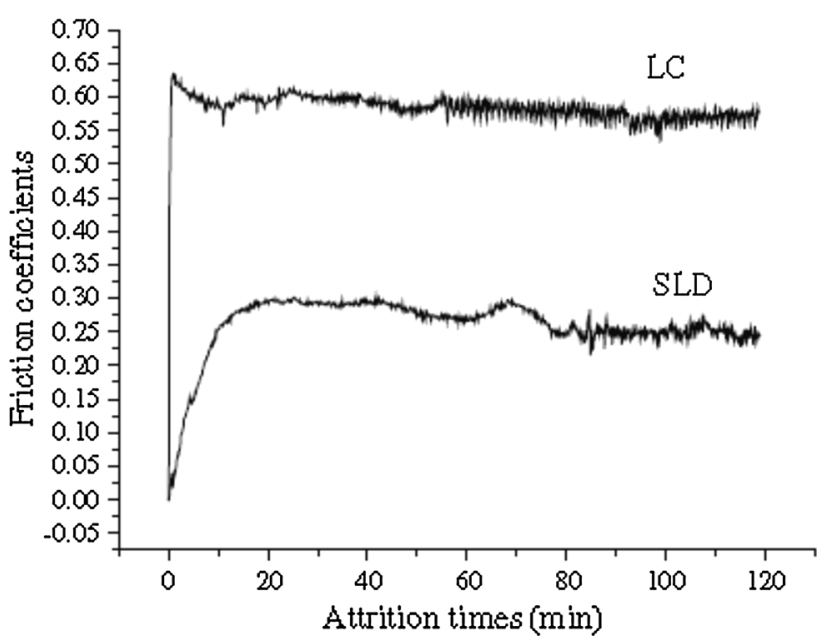

Fig. 16 Distribution curves for friction coefficients after SLD and LC (Ref 38)

produced using the HVOF process. Lower level of oxygen contamination reported for LACS deposited coatings could be attributed to the limited dwelling time of the particles, while still remaining in solid state during flight and deposition at elevated temperatures. However, in the traditional thermal spray deposited coatings, longer dwelling time of the particles at elevated temperatures during flight and deposition accounts for their higher oxygen contents.

In summary, the capability of LACS process to engender microstructural evolution via the elimination of open porosity through the formation of barrier-like oxide film on the surface of the coatings, and grain refinement due to annealing effect as the deposited particles are cooled at a rate which permits their recovery could be said to have accounted significantly for the improved corrosion resistance reported for LACS deposited coatings.

\subsection{Effects of CS Process Parameters on the Processing and Functional Properties of the LACS Deposited Coatings}

4.3.1 Effects of Operating Pressure on Processing and Microstructure of the LACS Deposited Coatings. The operating pressure in LACS process determines the impact velocity which also influences whether or not particlesubstrate and particle-particle bonding occurs. The operating pressure must be high enough such that it is able to propel particles above a critical impact velocity which promotes successful deposition of coatings on the substrates. For example, Bray et al., (Ref 5) demonstrated via particle image velocimetry (PIV) measurements and computational fluid dynamics (CFD) modeling software that the particle velocity increases with the operating pressure adopted in the LACS process (Fig. 20). The implication of this is that increased operating pressure is associated with improved coating efficiency as evident by the relationships between the deposition efficiencies and particle velocity provided the particle critical velocity had been exceeded upon impact at the deposition site (Fig. 21) (Ref 40, 41, 42). Moreover, below the critical velocity, impacting particles are generally observed to cause erosion of the substrate (Fig. 21) or result in porous coatings during LACS process.

Lee et al., (Ref 43) further elucidated how the operating pressure influenced the deposition mechanism in coldsprayed aluminum coatings. They reported that during lowpressure spraying conditions, it is possible that the majority of impinging particles could play a major role as "peening" of the substrates thereby increasing the impact onto substrate and particle's bonding among the deposited particles. SEM images of fractured cross section Al coatings (Fig. 22), as presented by Lee et al., (Ref 43), at different operating pressures confirm that severe deformation and ductile fracture of particles in the Al coating were observed at lower gas pressure condition consequent upon large peening of bounced-off $\mathrm{Al}$ particles at $0.7 \mathrm{MPa}$ (Fig. 22a). Furthermore, Lee et al.,(Ref 43) reported that Al particles propelled by $\mathrm{N}_{2}$ gas at higher operating pressure were not severely deformed when they were impacted onto the substrate (Fig. 22b and c). This behavior was attributed to the different degree of plastic deformation of coated $\mathrm{Al}$ particles at varying operating pressure due to the bounced-off particles (peening effect). The highest hardness of $\mathrm{Al}$ coating obtained at lower operating pressure as a result of work hardening by the splatted $\mathrm{Al}$ particles with severe deformation corroborate the fact that large peening effect of the bouncedoff particles resulted from consuming the coating efficiency at low gas pressure.

4.3.2 Effects of Nozzle Design on Processing and Microstructure of the LACS Deposited Coatings. It had been reported that the nozzle design also influences significantly the particle acceleration (Ref 5, 44, 45, 46, 47, 48). For example, the existence of an optimal expansion ratio (cross-sectional area ratio of nozzle exit to its throat) 


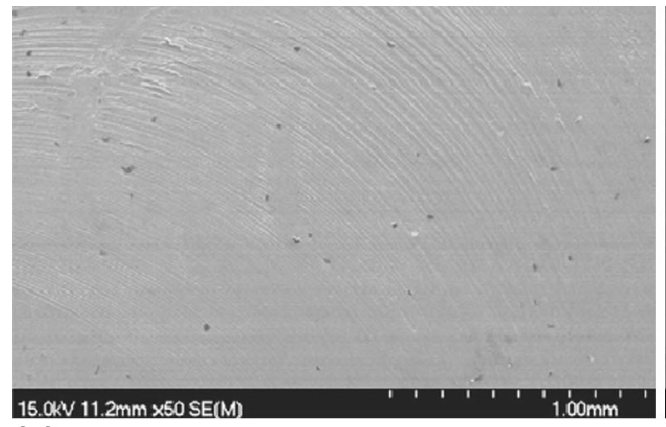

(a)

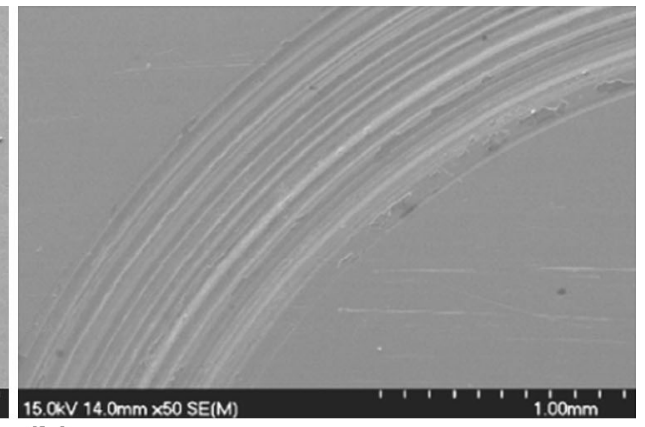

(b)

Fig. 17 Wear surface of Stellite 6 deposited via (a) SLD and (b) LC (Ref 38)

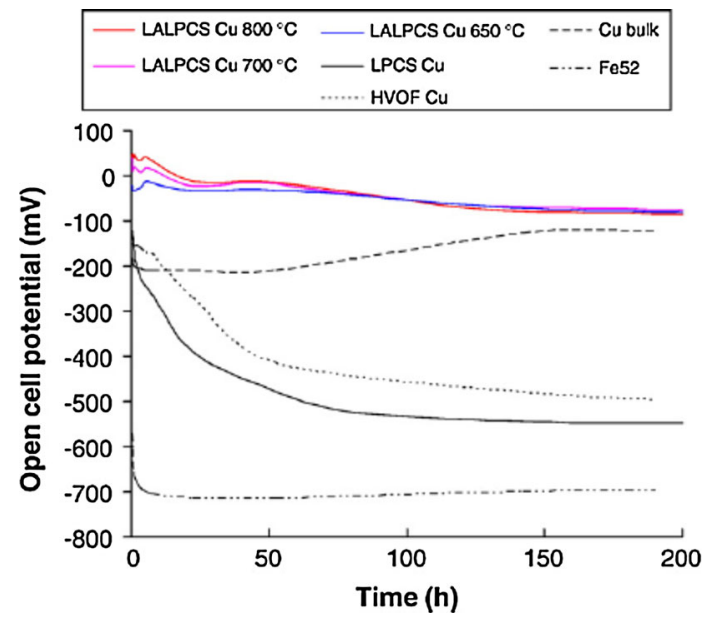

Fig. 18 Open cell potential vs. time for the LACS processed copper coatings at $0,650,700$, and $800{ }^{\circ} \mathrm{C}(\operatorname{Ref} 32)$

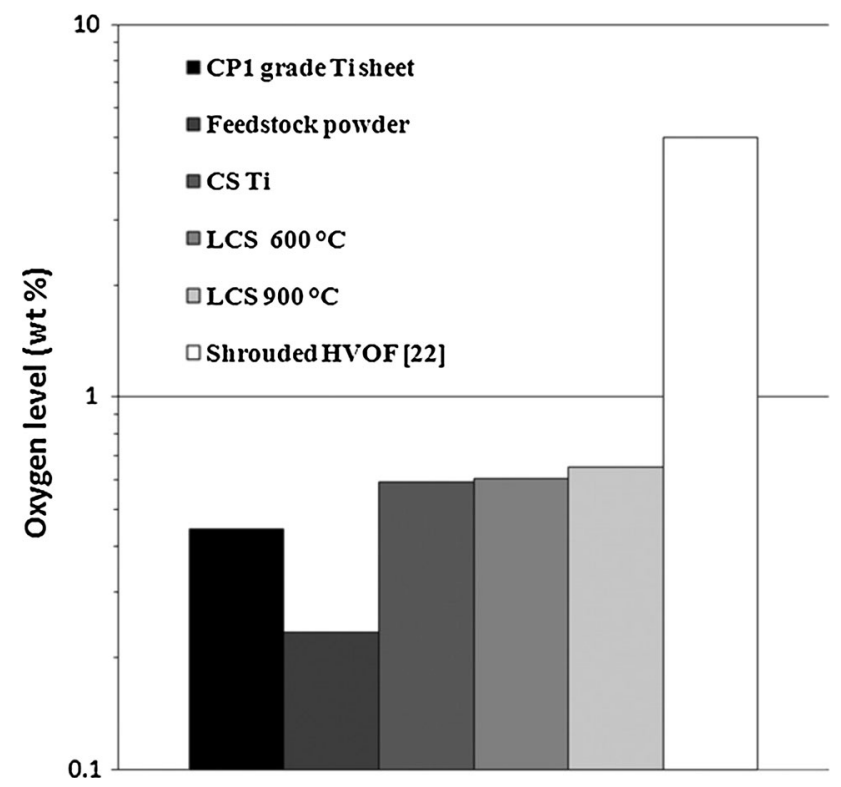

Fig. 19 Oxygen content of LCS titanium coatings, feedstock material, and HVOF (Ref 5)

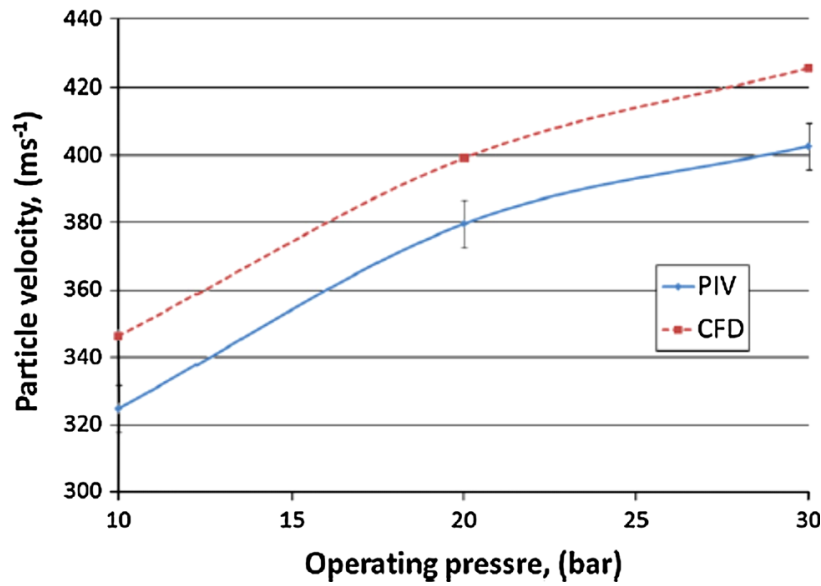

Fig. 20 Relationship between LACS operating pressure and particle velocity as measured by PIV and compared with the results of CFD modeling, using $\mathrm{N}_{2}$ at room temperature as the process gas $($ Ref 5$)$

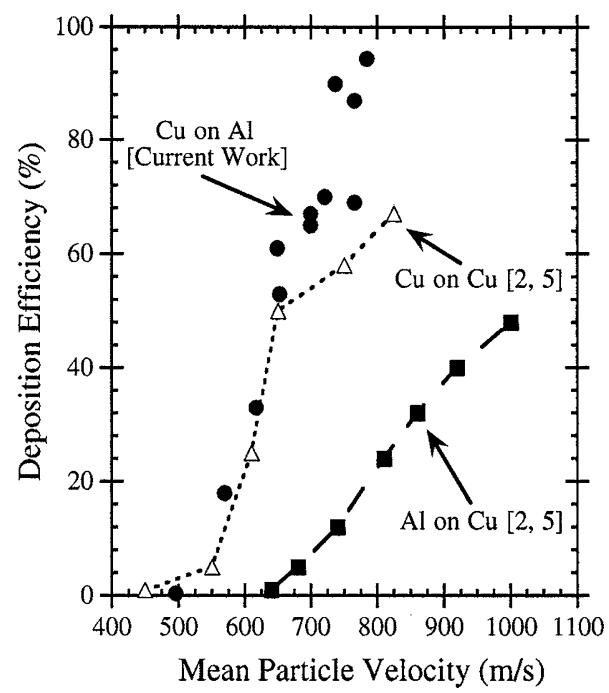

Fig. 21 Effect of particle velocity on deposition efficiency in cold gas dynamic spray (CGDS) (Ref 41) 

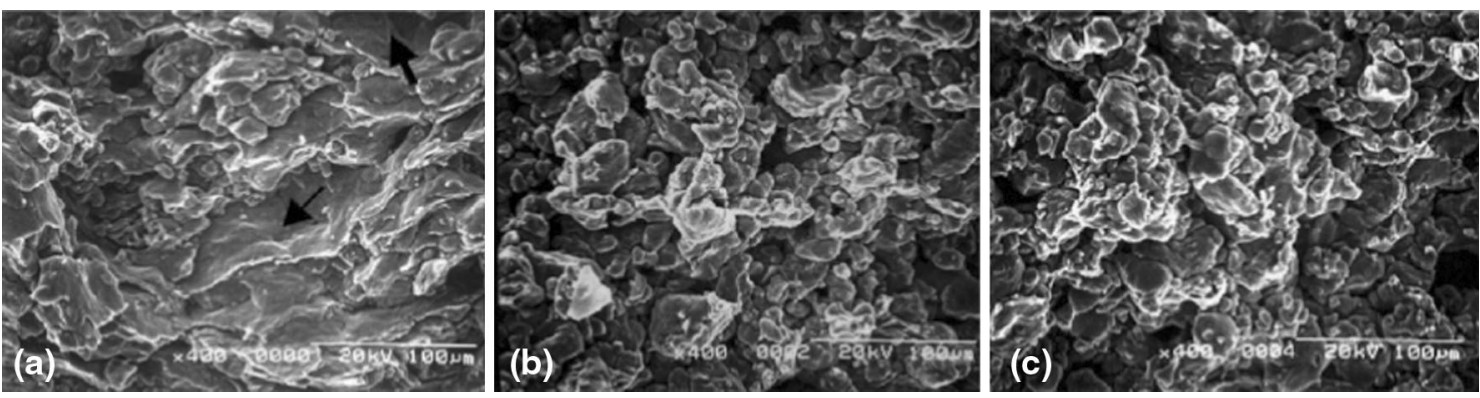

Fig. 22 Fractured cross-sectional images (SEM) of Al coatings with different pressures (a) $0.7 \mathrm{MPa}$, (the arrows indicated the splatted Al particles), (b) $1.5 \mathrm{MPa}$, and (c) $2.5 \mathrm{MPa}$ (Ref 42)

for particle acceleration of about 4 and 6.25 had been affirmed for a nozzle with a divergent length of 100 and 40 $\mathrm{mm}$, respectively (Ref 47). This implies that for constant nozzle throat diameter and divergent length, an optimal exit diameter does exist. Nevertheless, it must be highlighted that these findings may only be applicable for specific process conditions of each powdered materials. Therefore, those optimal values may be precise as a result of the change step of nozzle exit diameter. Li et al., (Ref 48) addressed this challenge by employing numerical methods to optimize the exit diameter of a convergingdiverging nozzle with a change step of $0.4 \mathrm{~mm}$ for exit diameter under different conditions. Findings from the study of Li et al., (Ref 48) revealed that the optimal expansion ratio increased with the increasing gas pressure and nozzle divergent length while it decreased with the increment in particle size and nozzle throat diameter. Moreover, the correlation of particle velocity with the coating microstructure and microhardness confirmed the optimal design method as evident in the deposition of dense 316L stainless steel coating having high microhardness. Bray et al., (Ref 5) also employed CFD software to model gas flow and particles velocity in a number of nozzles designed with varying divergent length (150$200 \mathrm{~mm})$; propellant gas $\left(\mathrm{N}_{2}\right.$ and $\left.\mathrm{He}\right)$; operating pressure (20-30 bar); and temperature (20 and $400{ }^{\circ} \mathrm{C}$ ) for LACS process. A nozzle propelling titanium particles in $\mathrm{N}_{2}$ gas with the following design parameters: divergent length (180 mm), operating pressure (30 bar), and temperature $\left(400{ }^{\circ} \mathrm{C}\right)$ was selected because it achieved the highest gas velocity and particle velocity for steel and titanium particles at lower cost.

As noted earlier in section 3, the deposition of functionally graded materials such as TBCs is also one of the applications of LACS process. Although TBCs had been fabricated from preliminarily prepared powder mixtures with difficulty in varying the components ratio of the powder mixtures during the deposition thereby making the production of coatings with through-thickness compositional gradient non-feasible, another drawback of this approach is the peculiarities of the physical phenomena associated with materials of different properties contained in the blended powder mixture during deposition. For instance, during CS deposition, blended particles may achieve an appropriate critical velocity for one component but ineffective for the others. Since the appropriate critical velocity of particles necessary to be attained for effective bonding with the substrate is a function of materials' properties of each of the component of the blended powders (Ref 49, 50), Klinkov et al., (Ref 25) pointed out that the use of blended powders is not always the most appropriate approach to deposit functionally graded coatings consisting of materials characterized with varying deposition parameters. Klinkov et al., (Ref 25) then proposed that the most effective approach for depositing multicomponent coatings would be to ensure that each component of the blended powders attains its appropriate deposition parameters for effective particle-substrate bonding. Klinkov et al., (Ref 25) then solved this problem by developing separate injection system for each component of the composite coatings into a different zone of the carrier gas stream in a CS system because exit particle deposition parameters at the nozzle outlet is a function of the location of the injection: the converging subsonic or diverging supersonic part of the nozzle.

Figure 23 shows the temperature and velocity distributions of aluminum particles of different sizes along the nozzle axis injected at the two different points at the gas stagnation temperature of $473 \mathrm{~K}$. It is evident for powders of the same particle sizes that those injected in the subsonic part of the nozzle first attained the maximum temperature in the subsonic part after which their temperature dropped down, while particles injected in the supersonic part of the nozzle encountered drop down in temperature (Fig. 23a). Moreover, particles injected in the subsonic part of the nozzle attained higher exit velocity than the particles injected in the supersonic part of the nozzle (Fig. 23b). Klinkov et al., (Ref 25) then employed this idea in the design and fabrication of an axisymmetric nozzle with two points of powder injection in a barrel with a constant cross section mounted to its diverging part (Fig. 24). They then successfully deposited a composite coating from two significantly different materials (aluminum and copper) by injecting copper (harder and higher melting point particles) and aluminum (softer and lower melting particles) from the subsonic and supersonic parts of the nozzle, respectively, as seen in Fig. 6.

4.3.3 Effects of Transverse Speed on Deposition Efficiency and Corrosion Behavior of the LACS Deposited Coatings. Spencer and Zhang (Ref 51) controlled stain- 

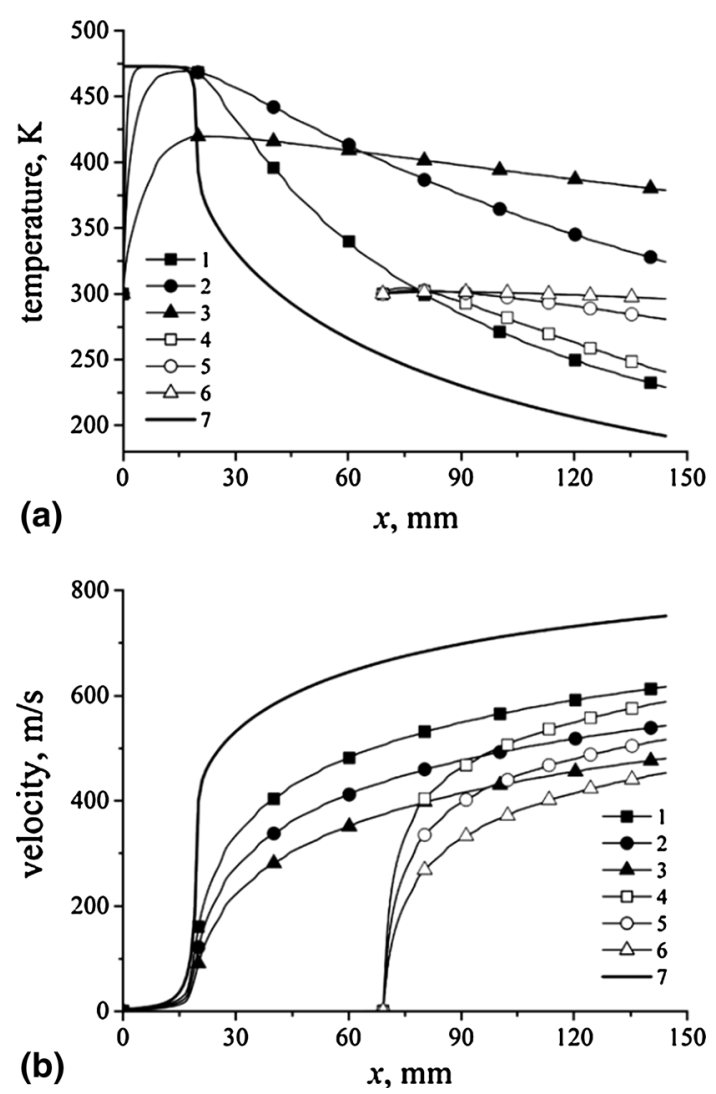

Fig. 23 Axial temperature and velocity distribution of the gas and of the 10-, 20-, and 40- $\mu \mathrm{m}$-sized aluminum particles inside the nozzle for the two locations of the powder injection: subsonic (1st point) and supersonic parts (2nd point) of the nozzle, $x$-distance along the nozzle axis: (a) particle temperature and gas static temperature; (b) particle and gas velocity. Curves 1, 2, and 3 correspond to 10,20 , and $40 \mu \mathrm{m}$ particles, 1 st point of injection; curves 4,5 , and 6 correspond to 10,20 , and $40 \mu \mathrm{m}$ particles, $2 \mathrm{nd}$ point of injection; curve 7 corresponds to the gas velocity (Ref 24)

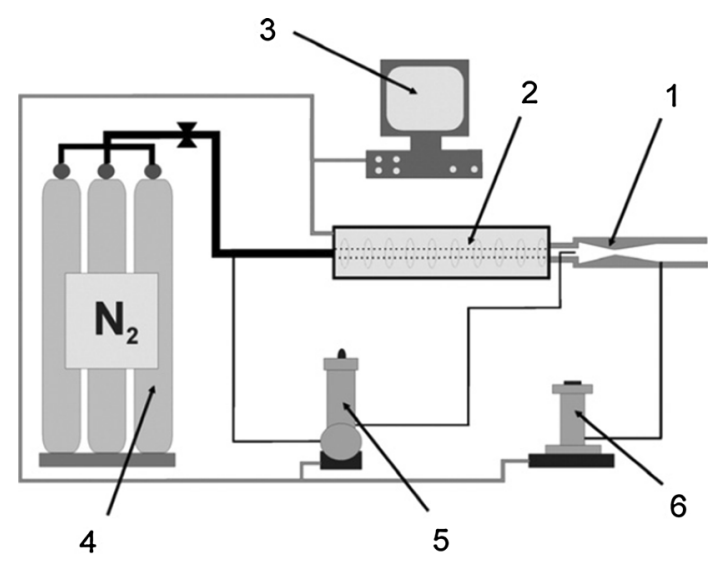

Fig. 24 Schematic view of the experimental device: 1-nozzle, 2- gas heater, 3-control panel, 4-carrier gas, 5-powder feeder for the 1st point of injection, and 6-powder feeder for the 2nd point of injection (Ref 24)

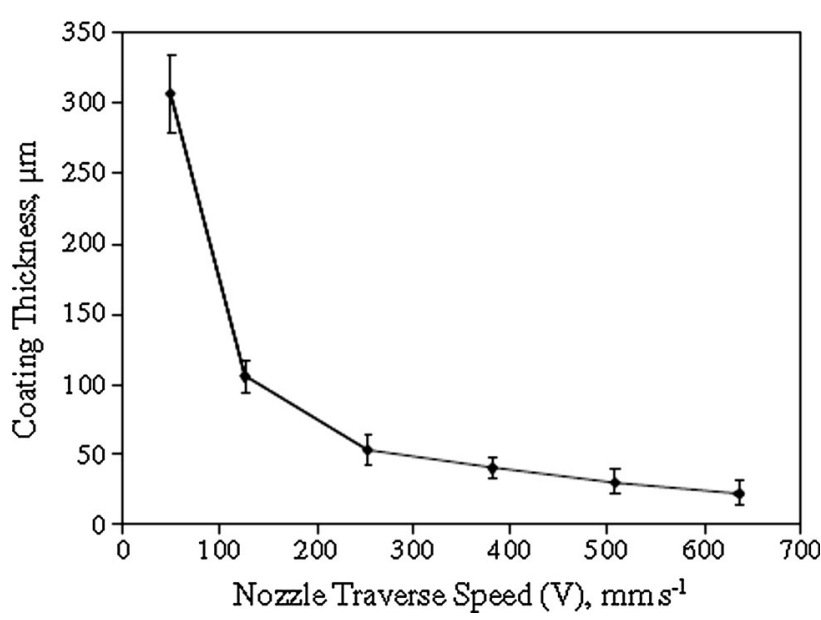

Fig. 25 Variation of coating thickness with the nozzle traverse speed (Ref 50)

less steel coating thickness by varying the transverse speed with a view to determining what thickness was needed for a relatively passive coating on an active substrate to be protective. A non-linear dependence of coating thickness on the traverse speed was confirmed as a result of increased interaction between powder particles at low traverse speeds (Fig. 25) with the porosity level in the coatings remaining constant at $\sim 4$ vol. $\%$, regardless of the coating thickness.

The anodic polarization behavior of the coatings of different thicknesses compared to that of the substrate material, and to that of bulk $316 \mathrm{~L}$ stainless steel is shown Fig. 26. Figure 26 depicts a trend from behavior dominated by the substrate, gradually approaching the behavior of bulk stainless steel as the coating thickness increases. The coating thickness of $105 \mu \mathrm{m}$ marks a transition from non-passivating, through a series of different mixed potentials, to passivating behavior at a thickness of $305 \mu \mathrm{m}$.

\subsection{Effects of Powder Characteristics on the Deposition Mechanism and Functional Properties of LACS Processed Coatings}

4.4.1 Effects of Particle Size and Distribution, Powder Density, on Processing, of the LACS Deposited Coatings. The important contribution of the critical particle velocity prior to impact on substrate in order that particles may acquire sufficient impact energy for the formation of pore-free coatings had been highlighted in section 4.3.1. Furthermore, because the feedstock powder consists of a range of particle sizes, it is expected that a distribution of particle velocities would occur as the particles are propelled in the process gas. Therefore, it is not just the operating pressure which influences the particle's critical impact velocity during LACS process. Materials' physical properties such as particle diameter, density, and morphology (Ref 42, 52); and thermo-mechanical properties of the powder and substrate materials (Ref 53, 54, 55) also 


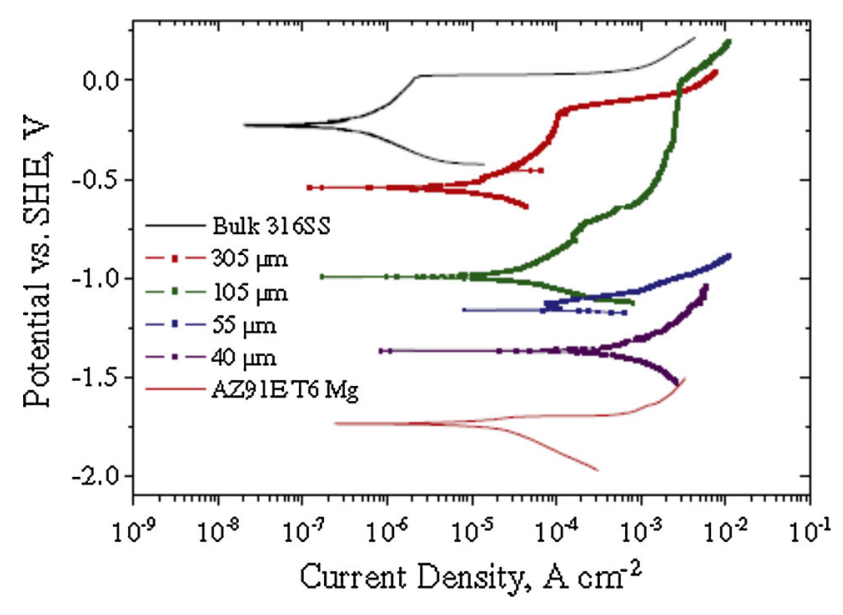

Fig. 26 Anodic polarization behavior of 316SS cold spray coatings of different thicknesses, compared to bulk type 316SS and AZ91E T6 substrate material (Ref 50)

influence the velocity at which the particles impact on the substrate for successful deposition of coatings.

For instance, Schmidt et al., (Ref 56) investigated the relationship between material properties (density and particle size) and the critical velocity necessary for successful bonding with the substrate. Figure 27(a) and (b) shows that the critical impact velocity is reduced as a materials' density and particle sizes increase, respectively. Schmidt and co-authors (Ref 56) also reported that particle size effects in cold spray dynamics can have a significant influence on the critical velocity necessary for effective particle bonding to the substrate as a consequence of the heat conduction or strain rate hardening which increases with reduced particle size. Moreover, it had also been highlighted that particle sizes and distribution between 5 and $50 \mu \mathrm{m}$ are suitable for cold spray process because they aid the production of dense coatings and wrought-like net-shaped parts in addition to the fact that they are easily fed by various CS and kinetic spray equipment designs ( $\operatorname{Ref} 30,54)$.

4.4.2 Effects of Particle Size and Distribution on Microstructure and Corrosion Performance of the LACS Deposited Coatings. Spencer and Zhang (Ref 51) examined the average particle size necessary to optimize the coating density obtained from CS deposited stainless steel powders by applying the powder metallurgy $(\mathrm{P} / \mathrm{M})$ practice of blending powders of varying particle size distributions (Fig. 28). Figure 28(a) shows the microstructure of stainless steel coatings made of a $-22 \mu \mathrm{m}$ particle size having a significant level of porosity, whereas that sprayed using a $-10 \mu \mathrm{m}$ particle size is almost fully dense through the bulk (Fig. 28b). In the case of coatings sprayed using a $-5 \mu \mathrm{m}$ particle size, there was no significant porosity (Fig. 28c). Moreover, coatings sprayed using a 50/50 vol.\% mixture of the -22 and $-5 \mu \mathrm{m}$ particle sizes have a heterogeneous structure with the existence of discontinuous regions of porosity concentrated in the interlayer boundaries, while the material within the layers is nearly fully dense (Fig. 28d) the coatings deposited with a 50/50 vol.\%
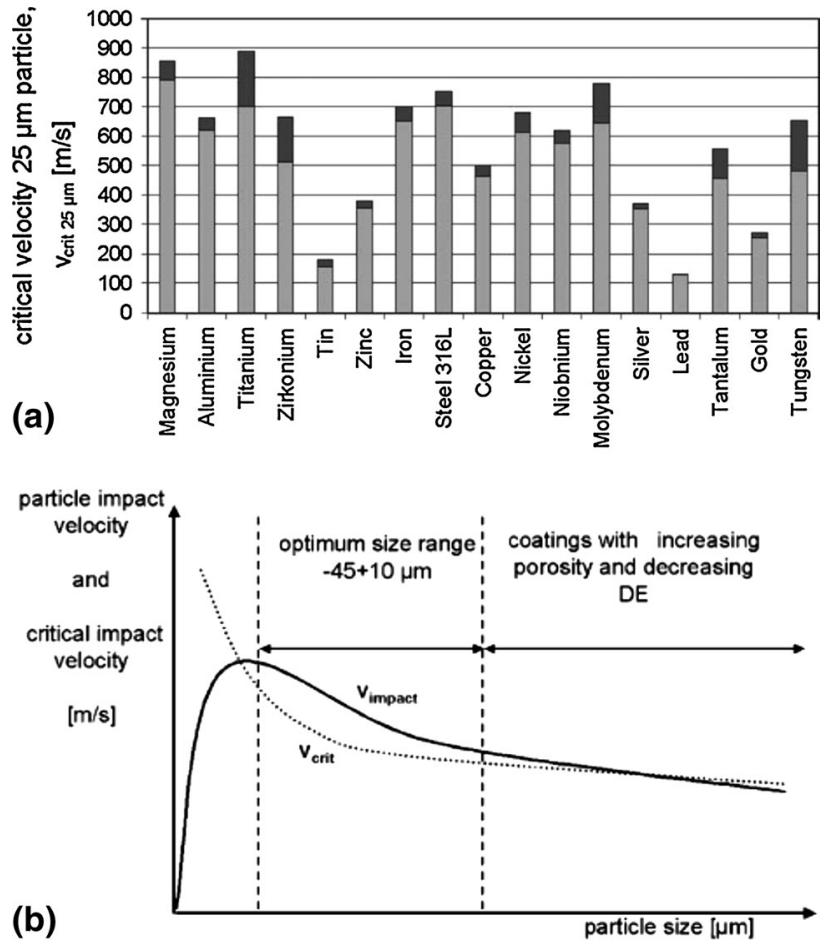

Fig. 27 (a) Critical impact velocity for a $25 \mu \mathrm{m}$ particle for materials of varying densities (b) $v_{\text {crit }}$ and $v_{\text {impact }}$ as a function of particle size (Ref 55)

mixture of the -10 and $-5 \mu \mathrm{m}$ powders (Fig. 28e) have a uniformly high density.

According to Spencer and Zhang (Ref 51), these outcomes imply that the feedstock powder's particle size influences the coating density and bonding in several ways. Since effective reduction in particle size subsequently leads to significant increment in the critical particle impact velocity from the nozzle (Fig. 27b), it is expected that higher impact velocity will lead to more deformation and densification upon impact at the deposition site. Higher critical impact velocity associated with smaller particle sizes had been attributed to (i) a higher surface area to volume ratio of surface oxide and (ii) the reduced thermal conduction length which results in reduced effects of impact-induced heating and particle softening (Ref 56). While it is preferable to achieve improved coating density and bonding with the substrate via reduction in particle size, large-sized particles are desirable for low cost, safety of transport and storage, relative low oxide content, good feeding characteristics, non-occurrence of nozzle fouling, and availability (Ref 30 ). Consequently, a consideration of the phenomenon of deceleration of fine particles through the bow shockwave which offsets their increased acceleration and their poor flow characteristics, and the associated nozzle fouling problem necessitate that the use of fine particles in either CS or LACS practice is always infeasible (Ref 57).

Similar to the approach in selective laser sintering (SLS) of blended Al-Si powders, combating these challenges in LACS also demands a compromise in the 

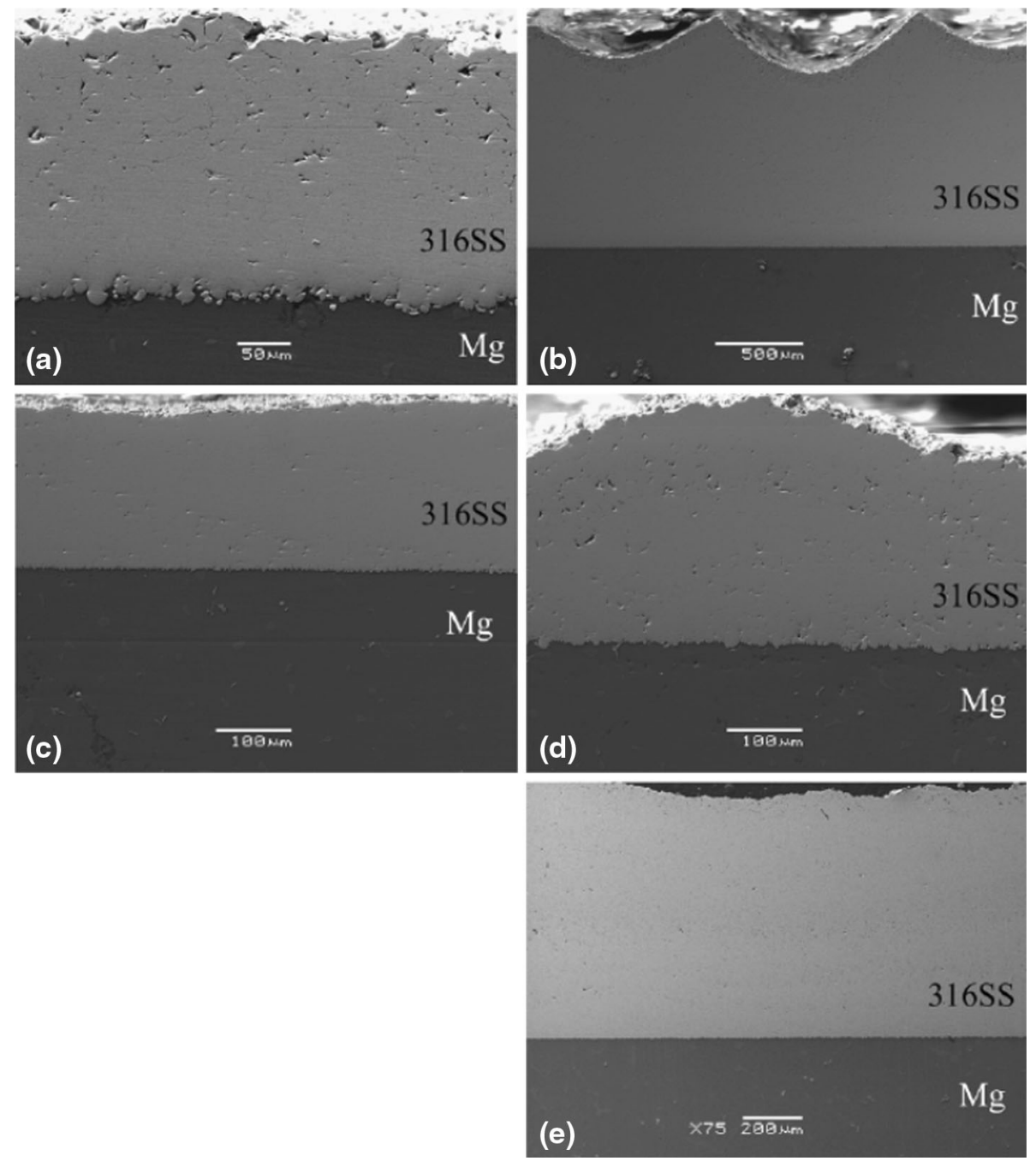

Fig. 28 Microstructure of 316L stainless steel coatings sprayed using (a) $-22 \mu \mathrm{m}$ powder; (b) $-10 \mu \mathrm{m}$ powder; (c) $-5 \mu \mathrm{m}$ powder, (d) a mixture of $50 \%-5 \mu \mathrm{m}$ and $50 \%-22 \mu \mathrm{m}$ powders, and (e) a mixture of $50 \%-5 \mu \mathrm{m}$ and $50 \%-10 \mu \mathrm{m}$ powders (Ref 50 )

blending of different powders having various particle sizes in order to obtain an optimum particle size with the highest packing efficiency (Fig. 29) which is obtained when the largest difference occurs between the mean particle size of the two powder mixtures (Ref 58). In addition, the powder feeding of the mixture should be far more consistent than that of finer powder alone so that there will be no problems with nozzle fouling when spraying the mixtures as a result of the larger particles acting to clean the inner surface of the nozzle (Ref 51). Consequently, the deposited coating comprising particles of smaller average particle size tends to bond to the substrate in preference to the large-sized particles in the powder mixture. Therefore, coating deposition efficiency will vary with the powder particle size in a transitional situation such that the large-sized particles deform very little, to one where small-sized particles experience severe deformation upon impact at the deposition site. This implies that a direct translation should not be expected when adopting the powder mixing approach to improve the density of the coatings.

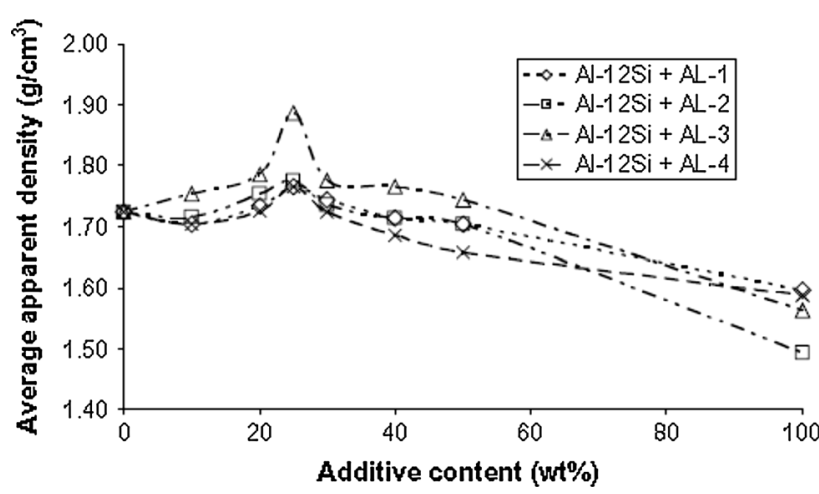

Fig. 29 Effect of varying additive level on the tapping density of laser-sintered bimodal Al-Si powders (Ref 57)

Spencer and Zhang (Ref 51) also assessed the role of powder mixing in the anodic polarization response of the deposited coatings having the same thickness. Figure 30 establishes that for coatings deposited with monosized 


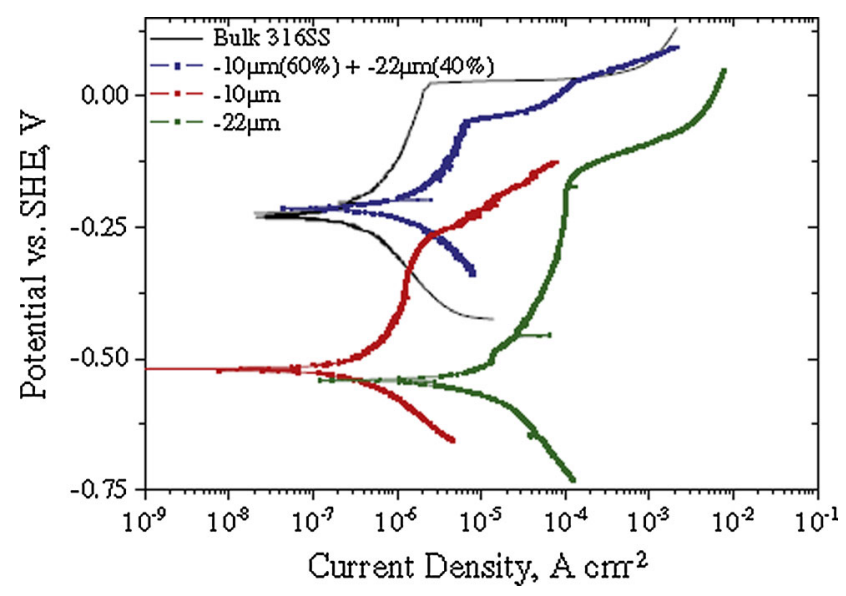

Fig. 30 Anodic polarization behavior of 316SS cold spray coatings using different powder particle sizes (Ref 50)

powders, the noble potential increases while the corrosion current density reduces as the average particle size reduces. Moreover, coatings deposited with blended powders are seen to exhibit corrosion behavior closest to that of the equivalent bulk material (Fig. 30). The implication of this finding is that the coating's polarization response is determined by the porosity within the coating and the quality of interparticle bonding as coatings with better interparticle bonding will be less subject to localized attack.

\section{Future Trends and Strategies}

On the basis of the evidences obtained from the reviewed studies, we are convinced that LACS has considerable potential for rapid transfer of laboratory-developed technology to various industrial sectors such as automotive, marine, biomedical, aeronautical/aerospace, power generation, petrochemical, and mining. Moreover, the need to reduce high cost of preparing coatings, reduce fabrication stages into a single step, and improve on coatings' functional properties are among the reasons LACS deposition technique will continue to gain prominence both in academic and industrial research. However, some application-oriented challenges such as severe abrasive wear, specific tribology, fatigue, high-temperature creep, and severe erosion need to be investigated for successful utilization in the industry.

The effects of both LACS processing and materials' parameters have been much in focus in this review; though the nature of interactions between the parameters and their influence on coatings' performance is not yet clearly understood. Processing routes such as an axisymmetric nozzle powder injection method that consists of separate injection of each component of the powder mixture into a different zone of the carrier gas stream and the powder metallurgy blends have been employed in the processing of coatings with a view to optimizing their performance. The axisymmetric nozzle powder injection method that consists of separate injection of each component of the powder mixture into a different zone of the carrier gas stream shows promise in effective deposition of functionally graded materials. A good insight has been developed on how the microstructures of LACS deposited coatings affect their consolidation mechanism, mechanical, and corrosion properties. By determining the appropriate laser energy density which permits no occurrence of metallurgical dilution between the coating and the substrate, increasing the particle velocity above a critical value, employing low transverse speed, redesigning the nozzle by determining the optimal expansion ratio for specified materials' properties, and blending together powders of appropriate particle size and distribution in formulating the coatings; the performance of the LACS deposited coatings can be improved.

Although LACS is capable of tailoring the composition, the microstructure, and the properties of coatings; nevertheless, due to its complex consolidation and cooling mechanisms, the accurate control of microstructure and properties of LACS deposited coatings still remains a big challenge because of an avalanche of factors influencing the process, the microstructure, and the microstructure repeatability. A search through the open literature shows that coatings were made in $316 \mathrm{~L}$ stainless steel, aluminum, titanium, and Al-Ti composite powders in order to tune the LACS system, characterize the process, and determine the range of operating temperature and particle velocity over which optimal coatings are produced (Ref 5, 13). These studies were not systematically planned to provide a detailed understanding of the factors which control the LACS process, the microstructure, and the microstructure repeatability. Moreover, there is the need to understand the relevant contribution of each LACS processing and materials' parameters to the successful deposition of coatings as well as its quality characteristics. Therefore, choosing appropriate input LACS processing and materials' parameters that guarantee an excellent consolidation of coatings remains a challenge for LACS manufacturing engineers.

Furthermore, defining the LACS input and material parameters to produce a pore-free coating with the required specifications is a time-consuming process involving error development effort and the skill of the manufacturing engineer. Among the few available LACS studies, optimized LACS and material parameter combinations have not been considered. To predict the LACS and materials' parameters accurately, without consuming time, materials, and labor effort, there are various methods of obtaining the desired output variables through the development of models. Design of experiment (DOE), one of such methods, has been adapted for various manufacturing processes for the optimization of process parameters (Ref 59,60). Analysis of the outcomes of the cited literature on manufacturing processes reveals that DOE could be applied to LACS in investigating the effect of process and material parameters on the qualities of coatings. Moreover, various mathematical models developed using this technique are expected to be fairly accurate in predicting the quality characteristics of coatings 
and optimizing the LACS conditions. However, none of the available literature has addressed the combined effect of influential LACS process and materials' parameters. Since new components, materials, and LACS processes are designed for various applications, it is pertinent that extensive research be carried out for each new application.

Modeling and simulation of LACS still constitute a challenge as no literature has reported on temperature fields, thermal cycles, and stress fields during LACS process. Significant efforts are still needed to effectively simulate the LACS process including the temperature, the consolidation mechanism, the microstructure, the blending of alloy powders, and the mass transfer. Moreover, in order to prevent untimely spallation of LACS deposited coatings, and enable the use of substrate materials on which they are deposited as economically and efficiently as possible; it is important that the nature of the residual stresses formed within their structure and their influence on the durability and reliability of coatings is properly understood. Therefore, the development of numerical simulation elucidating the effects of process/materials' parameters as well as operating conditions on the thermomechanical stress profiles in LACS fabricated coatings is important. By relating the fracture mechanics principle to the data on the variation of the thermo-mechanical properties of the coatings with the process/materials' parameters, it will be possible to identify the failure mechanisms and the degradation of the coatings under industrial operating conditions with a view to developing durable LACS processed coatings. The development of simulation to predict the spallation of the coatings will also take into cognisance of the influence of high-temperature oxidation on residual thermal stresses and structural response of the coatings. Finally, LACS encompasses the interdisciplinary knowledge of laser technology, material science, solid-state processing, solidification, powder metallurgy, and mechanics. Therefore, experience and expertise in these disciplines are required to achieve good LACS results so that a database integrating comprehensive LACS information can be created for industry-wide applications.

\section{Conclusions}

(1) LACS has considerable potential for rapid transfer of laboratory-developed technology to various industrial sectors such as automotive, marine, biomedical, aeronautical/aerospace, power generation, petrochemical, and mining. Moreover, the need to reduce high cost of preparing coatings, reduce fabrication stages into a single step, and improve on coatings' functional properties are among the reasons LACS deposition technique will continue to gain prominence both in academic and industrial research.

(2) The deposition mechanism in LACS process is controlled by particle and substrate softening via laser irradiation phenomena of laser beam absorption, thermalization, and heat transfer and adiabatic shearing phenomena in which deformation occurs partly at the top surface of each particle by flattening in a manner similar to thermally deposited coatings and also by forming a coherent layer via melting of particles in LACS deposited coating.

(3) Three variants of LACS process have been identified on the basis of the arrangement of the laser beam and the cold spray gun or the time at which laser irradiation is applied to the cold spray deposited coatings. Knowledge of these variants provides basic understanding of enhancing the particle-substrate and particle-particle bonding strength with a view to optimizing the coating performance via LACS process.

(4) The coating deposition efficiency varies with the powder particle size in a transitional situation such that the large-sized particles deform very little, to one where small-sized particles experience severe deformation upon impact at the deposition site. This implies that a direct translation should not be expected when adopting the powder mixing approach to improve the density of the LACS deposited coatings.

(5) This review has also led to the recognition of the influential process and materials' parameters which have strong influences on the performance requirements of LACS deposited coatings with their effects being linked to what impact each has over the microstructure and mechanical properties.

\section{Acknowledgments}

Dr. E. O. Olakanmi will like to thank the University of Johannesburg for the award of a Post-Doctoral Research Fellowship.

\section{References}

1. Q. Zhang, C.-J. Li, C.-X. Li, G.-J. Yang, and S.-C. Lui, Study of Oxidation Behaviour of Nanostructured NiCrAlY Bond Coatings Deposited by Cold Spraying, Surf. Coat. Technol., 2008, 202, p 3378-3384

2. N. Bala, H. Singh, and S. Prakash, Accelerated Hot Corrosion Studies of Cold Spray Ni-50Cr Coating on Boiler Steels, Mater. Des., 2010, 31, p 244-253

3. S. Dosta, M. Couto, and J.M. Guilemany, Cold Spray Deposition of a WC-25Co Cermet onto Al7075-T6 and Carbon Steel Substrates, Acta Mater., 2013, 61, p 643-652

4. R. Lupoi, A. Cockburn, C. Bryan, M. Sparkes, F. Luo, and W. O'Neill, Hardfacing Steel with Nanostructured Coatings of Stellite-6 by Supersonic Laser Deposition, Light Sci. Appl., 2012, 1, e10, doi:10.1038/lsa.2012.10, Published online 11 May 2012 (Accessed 7th February, 2013)

5. M. Bray, A. Cockburn, and W. O’Neill, The Laser-Assisted Cold Spray Process and Deposit Characterisation, Surf. Coat. Technol., 2009, 203, p 2851-2857

6. A. Ohmori, S. Hirano, and K. KamActa, Spraying TiN by a Combined Laser and Low-Pressure Plasma Spray System, $J$. Therm. Spray Technol., 1993, 2(2), p 137-144

7. Z.Y. Taha-al, M.S. Hashmi, and B.S. Yilbas, Effect of WC on the Residual Stress in the Laser Treated HVOF Coating, J. Mater. Process. Technol., 2009, 209, p 3172-3181

(1) 
8. T. Schnick, S. Tondu, P. Peyre, L. Pawlowski, S. Steinhäuser, B. Wielage, U. Hofmann, and E. Bartnicki, Laser Shock Processing of Al-SiC Composite Coating, J. Therm. Spray Technol., 1999, 8(2), p 296-300

9. T. Hussain, "A Study of Bonding Mechanisms and Corrosion Behaviour of Cold Sprayed Coatings", Ph.D. Thesis, University of Nottingham, 2011

10. A.P. Alkhimov, A.N. Papyrin, V.F. Kosarev, N.I. Nesterovich, and M.M. Shushpanov, Gas-Dynamic Spraying Method for Applying a Coating, U.S. Patent 5,302,414, 1994

11. H. Koivuluoto, "Microstructural Characteristics and Corrosion Properties of Cold-Sprayed Coatings", Ph.D. Thesis, Tampere University of Technology, 2010

12. T. Goyal, T.S. Sidhu, and R.S. Walia, An overview on cold spray process over competitive technologies for electro-technical applications. Presentation made at The National Conference on Advancements and Futuristic Trends in Mechanical and Materials Engineering, YCoE, Talwandi Sabo, http:// ptuconferences.com/digitallibrary/aftmme2010/TSC-05.pdf Accessed January 15, 2013

13. R. Lupoi, M. Sparkes, A. Cockburn, and W. O'Neill, High Speed Titanium Coatings by Supersonic Laser Deposition, Mater. Lett., 2011, 65, p 3205-3207

14. E.O. Olakanmi, M. Tlotleng, C. Meacock, S. Pityana, and M. Doyoyo, Deposition Mechanism and Microstructure of Laser Assisted Cold Sprayed (LACS) Al- $12 \mathrm{wt} \% \mathrm{Si}$ Coatings: Effects of Laser Power, JOM, 2013, doi:10.1007/s11837-013-0611-6

15. D.K. Christoulis, S. Guetta, V. Guipont, M.H. Berger, M. Jeandin, M. Boustie, S. Costil, Y. Ichikawa, K. Ogawa, E. Irissou, J.G. Legoux, and C. Moreau, Cold Spraying Combined to Laser Surface Pre-treatment Using PROTAL ${ }^{\circledR}$, Expanding Thermal Spray Performance to New Markets and Applications, B.R Marple, M.M. Hyland, Y.-C. Lau, C.-J. Li, R.S. Lima, G. Montavon, Ed., May 4-7, 2009 (Las Vegas, Nevada, USA), DVSASM, 2009, p 1151-1156

16. D.K. Christoulis, S. Guetta, E. Irissou, V. Guipont, M.H. Berger, M. Jeandin, J.-G. Legoux, C. Moreau, S. Costil, M. Boustie, Y. Ichikawa, and K. Ogawa, Cold-Spraying Coupled to Nano-Pulsed Nd-YaG Laser Surface Pre-treatment, J. Therm. Spray Technol., 2010, 19(5), p 1062-1073

17. D.K. Christoulis, M. Jeandin, E. Irissou, J-G. Legoux, and W. Knapp, Laser-Assisted Cold Spray (LACS) 2012, Available from: http://www.intechopen.com/books/nd-yag-laser/laser-assistedcold-spray-lacs (Assessed on 23rd March, 2013)

18. T. Marrocco, T. Hussain, D.G. McCartney, and P.H. Shipway, Corrosion Performance of Laser Post-treated Cold Sprayed Titanium Coatings, J. Therm. Spray Technol., 2011, 20(4), p 909-917

19. P. Poza, C.J. Múnez, M.A. Garrido-Maneiro, S. Vezzù, S. Rech, and A. Trentin, Mechanical Properties of Inconel 625 ColdSprayed Coatings after Laser Remelting: Depth Sensing Indentation Analysis, doi:10.1016/j.surfcoat.2012.03.018

20. G.W. Goward, Protective Coatings - Purpose, Role, and Design, Mater. Sci. Technol., 1986, 2, p 194-200

21. V.H. Hidalgo, F.J. Belzunce Varela, A. Carriles Menendez, and S. Poveda Martinez, A Comparative Study of High-Temperature Erosion Wear of Plasma-Sprayed NiCrBSiFe and WC-NiCrBSiFe Coatings Under Simulated Coal-Fired Boiler Conditions, Tribol. Int., 2001, 34(3), p 161-169

22. J.H. Kim, E. Akiyama, H. Yoshioka, H. Habazaki, A. Kawashima, K. Asami, and K. Hashimoto, The Corrosion Behaviour of Sputter-Deposited Amorphous Titanium-Chromium Alloys in $1 \mathrm{M}$ and $6 \mathrm{M} \mathrm{HCl}$ Solutions, Corros. Sci., 1993, 34, p 975-987

23. M. Mehmood, E. Akiyama, H. Habazaki, A. Kawashima, K. Asami, and K. Hashimoto, The Degradation of the Corrosion Resistance of Sputter Deposited Chromium-Titanium Alloys by Nanoscale Heterogeneity, Corros. Sci., 1999, 41, p 1889-1890

24. J. Morimoto, T. Onoda, Y. Sasaki, and N. Abe, Improvement of Solid Cold Sprayed $\mathrm{TiO}_{2}-\mathrm{Zn}$ Coating with Direct Diode Laser, Vacuum, 2004, 73, p 527-532

25. S.V. Klinkov, V.F. Kosarev, A.A. Sova, and I. Smurov, Deposition of Multicomponent Coatings by Cold Spray, Surf. Coat. Technol., 2008, 202, p 5858-5862
26. N.K. Tolochko, Y.V. Khlopkov, S.E. Mozzharov, M.B. Ignatiev, T. Laoui, and V. Titov, Absorptance of Powder Materials Suitable for Laser Sintering, Rapid Prototyp. J., 2000, 6(3), p 155-161

27. J. Meijer, K. Du, A. Gillner, D. Hoffmann, V.S. Kovalenko, T. Matsunawa, A. Ostendorf, R. Poprawe, and W. Schulz, Laser Machining by Short and Ultrashort Pulses, State of the Art and New Opportunities in the Age of the Photons, CIRP Ann. Manuf. Technol., 2002, 51(2), p 531-550

28. D. Neves, A.E. Diniz, and M.S. de Fernandes, Lima, Efficiency of the Laser Texturing on the Adhesion of the Coated Twist Drills, J. Mater. Process. Technol., 2006, 179, p 139-145

29. E.O. Olakanmi, Selective Laser Sintering/Melting (SLS/SLM) of Pure Al, Al-Mg, and Al-Si Powders: Effect of Processing Conditions and Powder Properties, J. Mater. Process. Technol., 2013, 213(8), p 1387-1405

30. F.J. Brodmann, Cold Spray Process Parameters: Powders, The Cold Spray Materials Deposition Process: Fundamentals and Applications, V.K. Champagne, Ed., Woodhead Publishing Limited, Cambridge, 2007, p 105-116

31. H.W. Bergmann, K. Schutte, E. Schubert, and A. Emmel, LaserSurface Processing of Metals for Industrial Applications, Appl. Surf. Sci., 1995, 86(1-4), p 259-265

32. D. Von Der Linde and K. Sokolowski-Tinten, The Physical Mechanisms of Short-Pulse Laser Ablation, Appl. Surf. Sci., 2000, 154(155), p 1-10

33. M. Kulmala and P. Vuoristo, Influence of Process Conditions in Laser-Assisted Low-Pressure Cold Spraying, Surf. Coat. Technol., 2008, 202, p 4503-4508

34. P. Poza, C.J. Múnez, M.A. Garrido, S. Vezzù, S. Rech, and A. Trentin, Effect of Laser Remelting on the Mechanical Behaviour of Inconel 625 Cold-Sprayed Coatings, Proc. Eng., 2011, 10, p 3799-3804

35. M. Perton, S. Costil, W. Wong, D. Poirier, E. Irissou, J.-G. Legoux, A. Blouin, and S. Yue, Effect of Pulsed Laser Ablation and Continuous Laser Heating on the Adhesion and Cohesion of Cold Sprayed Ti-6Al-4V Coatings, J. Therm. Spray Technol., 2012, 21(6), p 1322-1333

36. W.Y. Li, C. Zhang, X. Guo, C.J. Li, H. Liao, and C. Coddet, Study on Impact Fusion at Particle Interfaces and Its Effect on Coating Microstructure in Cold Spraying, Appl. Surf. Sci., 2007, 254(2), p 517-526

37. F. Raletz, M. Vardelle, and G. Ezo'o, Critical Particle Velocity Under Cold Spray Conditions, Surf. Coat. Technol., 2006, 201(5), p 1942-1947

38. R. Morgan, P. Fox, J. Pattison, C. Sutcliffe, and W. O'Neill, Analysis of Cold Gas Dynamically Sprayed Aluminium Deposits, Mater. Lett., 2004, 58(7-8), p 1317-1320

39. F. Luo, A. Cockburn, R. Lupoi, M. Sparkes, and W. O'Neill, Performance Comparison of Stellite $6^{\circledR}$ Deposited on Steel Using Supersonic Laser Deposition and Laser Cladding, Surf. Coat. Technol., 2012, 212, p 119-127

40. F. Gurtner, T. Stoltenhoff, T. Schmidt, and H. Kreye, The Cold Spray Process and Its Potential for Industrial Applications, $J$. Therm. Spray Technol., 2006, 15(2), p 223-232

41. R.C. McCune, A.N. Papyrin, J.N. Hall, W.L. Riggs, and P.H. Zajchowski, An Exploration of the Cold Gas-Dynamic Spray Method for Several Materials Systems, 8th NTSC (1995) Advances in Thermal Spray Science \& Technology, C.C. Berndt and S. Sampath, Ed., Sept 11-15, 1995 (Houston, TX), ASM International, 1995, p 1-6

42. D.L. Gilmore, R.C. Dykhuizen, R.A. Neiser, T.J. Roemer, and M.F. Smith, Particle Velocity and Deposition Efficiency in the Cold Spray Process, J. Therm. Spray Technol., 1999, 8(4), p 576582

43. H. Lee, H. Shin, S. Lee, and K. Ko, Effect of Gas Pressure on Al Coatings by Cold Gas Dynamic Spray, Mater. Lett., 2008, 62, p $1579-1581$

44. B. Jodoin, Cold Spray Nozzle Mach Number Limitation, $J$. Therm. Spray Technol., 2002, 11(4), p 496-507

45. T. Stoltenhoff, H. Kreye, and H.J. Richter, An Analysis of the Cold Spray Process and Its Coatings, J. Therm. Spray Technol., 2002, 11(4), p 542-550 
46. A.P. Alkhimov, V.F. Kosarev, and S.V. Klinkov, The Features of Cold Spray Nozzle Design, J. Therm. Spray Technol., 2001, 10(2), p 375-381

47. C.-J. Li and W.-Y. Li, Optimal Design of a Novel Cold Spray Gun Nozzle at a Limited Space, J. Therm. Spray Technol., 2005, 14(3), p 391-396

48. W.-Y. Li, H. Liao, G. Douchy, and C. Coddet, Optimal Design of a Cold Spray Nozzle by Numerical Analysis of Particle Velocity and Experimental Validation with 316L Stainless Steel Powder, Mater. Des., 2007, 28, p 2129-2137

49. A. Papyrin, V. Kosarev, S. Klinkov, A. Alkhimov, and V. Fomin, Cold Spray Technology, 1st ed., Elsevier Science, Amsterdam, 2007, p 248-323

50. F. Garner, C. Borchers, T. Stolenhoff, H. Kreye, and H. Assadi, Numerical and Microstructural Investigations of the Bonding Mechanisms in Cold Spraying, Thermal Spray 2003: Advancing the Science and Applying the Technology, B.R. Maple, and C. Moreau, Ed., May 5-8, 2003 (Orlando, FL), ASM International, 2003, p 1-8

51. K. Spencer and M.-X. Zhang, Optimisation of Stainless Steel Cold Spray Coatings Using Mixed Particle Size Distributions, Surf. Coat. Technol., 2011, 205, p 5135-5140

52. K. Sakaki, T. Tajima, H. Li, S. Shinkai, and Y. Shimizu, Influence of Substrate Conditions and Traverse Speed on Cold Sprayed Coatings, Thermal Spray 2004: Advances in Technology and Application, ASM International, May 10-12, 2004 (Osaka, Japan), ASM International, 2004, p 358-362
53. R.C. Dykhuizen, M.F. Smith, D.L. Gilmore, R.A. Neiser, X. Jiang, and S. Sampath, Impact of High Velocity Cold Spray Particles, J. Therm. Spray Technol., 1999, 8(4), p 559-564

54. J. Vlcek, L. Gimeno, H. Huber, and E. Lugscheider, A Systematic Approach to Material Eligibility for the Cold Spray Process, Thermal Spray 2003: Advancing the Science and Applying the Technology, B.R. Maple, and C. Moreau, Ed., May 5-8, 2003 (Orlando, FL), ASM International, 2003, p 37-44

55. V.F. Kosarev, S.V. Klinkov, A.P. Alkhimov, and A.N. Papyrin, On Some Aspects of Gas Dynamics of the Cold Spray Process, $J$. Therm. Spray Technol., 2003, 12(2), p 265-281

56. T. Schmidt, F. Gärtner, H. Assadi, and H. Kreye, Development of a Generalized Parameter Window for Cold Spray Deposition, Acta Mater., 2006, 54, p 729-742

57. J. Pattison, S. Celotto, A. Khan, and W. O'Neill, Standoff Distance and Bow Shock Phenomena in the Cold Spray Process, Surf. Coat. Technol., 2008, 202(8), p 1443-1454

58. E.O. Olakanmi, K.W. Dalgarno, and R.F. Cochrane, Laser Sintering of Blended Al-Si Powders, Rapid Prototyp. J., 2012, 18(2), p 109-119

59. N. Cinca, M. Barbosa, S. Dosta, and J.M. Guilemany, Study of Ti Deposition onto Al Alloy by Cold Gas Spraying, Surf. Coat. Technol., 2010, 205, p 1096-1102

60. M.M.A. Khan, L. Romoli, M. Fiaschi, G. Dini, and F. Sarri, Experimental Design Approach to the Process Parameter Optimization for Laser Welding of Martensitic Stainless Steels in a Constrained Overlap Configuration, Opt. Laser Technol., 2011, 43, p $158-172$ 